University of Rhode Island

DigitalCommons@URI

Open Access Master's Theses

2002

\title{
Microstructure Determination in a Self Assembled Surfacant System Formed by AOT/Lecithin/Isooctane and Water
}

\author{
Vivek Agarwal \\ University of Rhode Island
}

Follow this and additional works at: https://digitalcommons.uri.edu/theses

\section{Recommended Citation}

Agarwal, Vivek, "Microstructure Determination in a Self Assembled Surfacant System Formed by AOT/ Lecithin/Isooctane and Water" (2002). Open Access Master's Theses. Paper 927.

https://digitalcommons.uri.edu/theses/927

This Thesis is brought to you for free and open access by DigitalCommons@URI. It has been accepted for inclusion in Open Access Master's Theses by an authorized administrator of DigitalCommons@URI. For more information, please contact digitalcommons-group@uri.edu. 
MICROSTRUCTURE DETERMINATION IN A SELF ASSEMBELED

SURFACTANT SYSTEM FORMED BY AOT/LECITHIN/ISOOCTANE AND

WATER

BY

VIVEK AGARWAL

A THESIS SUBMITTED IN THE PARTIAL FULFILLMENT OF THE REQUIREMENTS FOR THE DEGREE OF

MASTER OF SCIENCE

IN

CHEMICAL ENGINEERING

THE UNIVERSITY OF RHODE ISLAND 
MASTER OF SCIENCE THESIS

$\mathrm{OF}$

VIVEK AGARWAL

APPROVED:

Thesis Committee

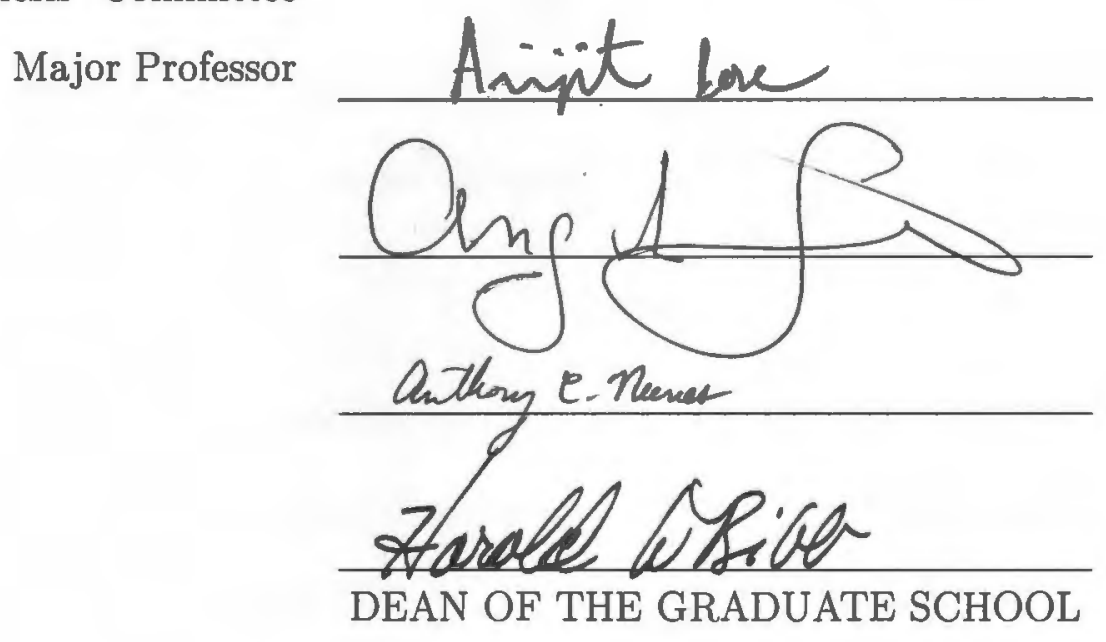

UNIVERSITY OF RHODE ISLAND 


\section{ABSTRACT}

We have observed a novel transformation from a microemulsion to a gel phase by increasing the water content of a system consisting of bis(2-ethylhexyl) sodium sulfosuccinate(AOT), phosphatidycholine(lecithin), and 2,2,4 -trimethylpentane (isooctane). The viscosity increases by six orders of magnitude and a rigid gel forms as the water content is increased above a specific threshold. Small angle neutron scattering (SANS) experiments on this surfactant mesophase reveal the microstructure as columnar hexagonal at lower water contents and temperatures, and lamellar at higher water contents and temperatures. SANS is also able to capture the transition between these two structures. These structures are thermally reversible. Differential scanning calorimetery results show no abrupt phase transitions in the gel system with increasing temperature.

For low water and surfactant contents $\left(\mathrm{W}_{0}=20\right.$, total surfactant concentration in isooctane $=0.01 \mathrm{M}$ ), microemulsion droplets are formed. SANS experimental data fits well with the polydisperse sphere morphology and a gradual increase in the droplet size is observed as the lecithin/AOT ratio is increased. The different packing parameters for AOT and lecithin drive the observed changes in droplet sizes. For lecithin/AOT molar ratios approaching unity, both SANS and static light scattering measurements reveal an attractive interaction develops between these droplets, leading to the formation of clusters. Hydrodynamic radii obtained from dynamic light scattering measurements show results that are consistent with the SANS data. 


\section{ACKNOWLEDGEMENTS}

Good things in one's life don't happen just like that. It requires a lot of support and a lot of sacrifices from the people who care about you. It would not be possible for me, to be where I am today, without the love and support of the people around me.

First of all, I would like paying my sincere thanks to my parents. They are just amazing, the way they encouraged me all life long. Their love is precious to me.

I should be more than thankful to my advisor Dr. Arijit Bose, who trusted me and guided me at every single step of my research. I learned a lot from him and it was a pleasure working with him.

I would like to thank Dr. Vijay John and Dr. Blake Simmons from Tulane University for their enormous contribution to my research.

I would like to thank Dr. Tony Nunes for providing me with expertise in scattering techniques.

I would like to thank Dr. Angelo Lucia for his technical support and encouragement.

I would like to thank Paul Johnson, for providing his expertise of TEM, to me.

I would like to thank Dr. Alazar Ghebremeskel, Dr. Yashen Xia, Shuang Xiao, Wei Li, Robert Lawton and Nikhil Barbare for being such a wonderful group members. I would like to thank Arron Carroll for generating the valuable DSC data for my research.

I would like to thank my friends, Amit Singh Chhetri and Prasan Kasturi for their sincere help and support. 
Last, but not the least, I would like to thank Meredith Leach for her valuable assistance as a department secretary. 


\section{Preface}

This thesis is written in manuscript form. Chapter II has been prepared for submission to Langmuir. This work involves use of small angle neutron scattering (SANS) to reveal the microstructure in a mixed surfactant microemulsion system.

Chapter III reveals the light scattering and cryogenic transmission electron microscopy (Cryo-TEM) results on the system discussed in chapter II.

Chapter IV reports freeze fracture transmission electron microscopy and differential scanning calorimetery (DSC) measurements in a mixed surfactant gel system. 


\section{Table of Contents}

CHAPTER

PAGE

I Introduction 1

$\begin{array}{ll}\text { References } & 7\end{array}$

II Small angle neutron scattering studies on a mixed surfactant

$\begin{array}{ll}\text { microemulsion system. } & 9\end{array}$

$\begin{array}{lll}\text { II-A Introduction } & 9\end{array}$

II-B Materials and methods $\quad 11$

$\begin{array}{ll}\text { II-B1 Chemicals } & 11\end{array}$

II-B2 Sample preparation $\quad 11$

$\begin{array}{llr}\text { II-B3 Experimental details } & 12\end{array}$

$\begin{array}{lll}\text { II-C Results and discussion } & 13\end{array}$

$\begin{array}{ll}\text { II-D Conclusions } & 20\end{array}$

$\begin{array}{ll}\text { References } & 43\end{array}$

III Light scattering and cryogenic TEM studies on a mixed surfactant

$\begin{array}{ll}\text { microemulsion system. } & 46\end{array}$

III-A Introduction $\quad 46$

$\begin{array}{lll}\text { III-B Experimental section } & 48\end{array}$

$\begin{array}{ll}\text { III-B1 Chemicals } & 48\end{array}$

III-B2 Sample preparation $\quad 49$

III-B3 Experimental details $\quad 49$

III-B3.1 Static light scattering $\quad 49$

III-B3.2 Dynamic light scattering $\quad 50$ 
III-C Analysis 51

III-C1 Light scattering $\quad 51$

III-C2 Cryogenic transmission electron microscopy 53

III-D Results and discussion 53

$\begin{array}{ll}\text { III-E Conclusions } & 55\end{array}$

$\begin{array}{ll}\text { References } & 67\end{array}$

IV Freeze fracture TEM and differential scanning calorimetery

studies on the mixed surfactant gel system. 68

$\begin{array}{lll}\text { IV-A Introduction } & 68\end{array}$

$\begin{array}{lll}\text { IV-B Experimental section } & 69\end{array}$

IV-B1 Chemicals $\quad 69$

IV-B2 Sample preparation $\quad 69$

$\begin{array}{ll}\text { IV-B3 Experimental details } & 70\end{array}$

IV-B3.1 Freeze fracture TEM 70

IV-B3.2 Differential scanning calorimetery $\quad 70$

$\begin{array}{lll}\text { IV-C Analysis } & 71\end{array}$

$\begin{array}{lll}\text { IV-D Results and discussion } & 72\end{array}$

$\begin{array}{lll}\text { IV-E Conclusions } & 72\end{array}$

$\begin{array}{ll}\text { References } & 77\end{array}$

$\begin{array}{ll}\text { V Bibliography } & 78\end{array}$ 


\section{List of Tables}

TABLE

PAGE

\section{CHAPTER II}

II-1 Compositions of all the components in the microemulsion, for all the samples.

II-2A Results from the fit of polydisperse sphere form factor for samples 1,2 and 3 and polydisperse sphere form factor with square well structure factor for sample 4 and 5 , to the SANS experimental data.

II-2B Results from the fit of ellipsoid form factor, in the appropriate $q$ region for all the samples, to the experimental data

II-3 The radius of gyration obtained from a Guinier analysis and the radius of gyration calculated from the dimensions of the two different morphologies under consideration.

II-4 ' $a$ ' the average area/head group calculated for the SANS data using Eq. II-8. ' $a$ ' decreases systematically from sample 1 to sample 5 indicating a more dense surfactant film and greater rigidity at the interface as the lecithin content is increased.

\section{CHAPTER III}

III-1 Results from the experimental data for all the five samples.

Column 2 contains the hydrodynamic radii information from dynamic light scattering experiments. Column 3 reports the radius of gyration obtained from the Guinier analysis of the static light scattering data. Column 4 reports the calculated radius of gyration (using Eq.III-3) based on the hydrodynamic radius tabulated in column2. 


\section{CHAPTER IV}

IV-1 Comparison of the experimental average specific heat capacity for all the samples with the specific heat capacity calculated using simple mixing rule. 


\section{List of figures}

FIGURE

PAGE

\section{CHAPTER I}

I-1 (a) AOT molecule, (b) lecithin molecule, (c) rigid gel formed at $\mathrm{W}_{0}=90$.

I-2 Results of the SANS studies on the gel system. (H) represents hexagonal microstructure, (L) represents lamellar microstructure and $(\mathrm{T})$ represents the phase where both hexagonal and lamellar microstructure coexists.

\section{CHAPTER II}

II-1 Log-log plot of the Intensity versus magnitude of the scattering vector ' $q$ ' for samples, (O) 0.01MAOT (sample 1), ( $\square$ ) 0.00125M Lecithin /0.00875M AOT (sample 2), $(\Delta)$ 0.0025M Lecithin 10.0075M AOT (sample 3), ( $\boxplus$ ) $0.00375 \mathrm{M}$ Lecithin $10.00625 \mathrm{M}$ AOT (sample 4), and $(\bullet) 0.005 \mathrm{M}$ Lecithin $/ 0.005 \mathrm{M}$ AOT (sample 5). Sample 1, 2 and 3 show a classical scattering profile, a low $q$ asymptote (the Guinier region), followed by a drop (fractal region), and then a decay at large $q$. Sample 4 and 5 shows an upturn in intensity at low q indicative of interactions between the particles.

II-2(a) Cross-section Guinier plots for 0.01M AOT sample, (O) $x=0$, ( $\square$ ) $x=1$, and $(\Delta) x=2$. The solid line represents the straight line fit to the experimental data. These data clearly suggests the potential morphologies of spheres rather than long cylinders or lamellar shapes.

II-2(b) Cross section Guinier plots for $0.00125 \mathrm{M}$ lecithin/0.00875 M

AOT sample, $(O) x=0,(\square) x=1$, and $(\Delta) x=2$. The solid line represents the straight line fit to the experimental data. These data clearly suggests the potential morphologies of spheres rather than long cylinders or lamellar shapes.

II-2(c) Cross section Guinier plots for $0.0025 \mathrm{M}$ lecithin/0.0075 M AOT sample, (O) $x=0,(\square) x=1$, and $(\Delta) x=2$. The solid line represents the straight line fit to the experimental data. These data 
clearly suggests the potential morphologies of spheres rather than long cylinders or lamellar shapes.

II-2(d) Cross section Guinier plots for $0.00375 \mathrm{M}$ lecithin/ $0.00625 \mathrm{M}$

AOT sample, $(O) x=0,(\square) x=1$, and $(\Delta) x=2$. The solid line represents the straight line fit to the experimental data. These data clearly suggests the potential morphologies of spheres rather than long cylinders or lamellar shapes.

II-2(e) Cross section Guinier plots for $0.005 \mathrm{M}$ lecithin/0.005 M AOT sample, (O) $x=0,(\square) x=1$, and $(\Delta) x=2$. The solid line represents the straight line fit to the experimental data. These data clearly suggests the potential morphologies of spheres rather than long cylinders or lamellar shapes.

II-3(a) Non-linear least square fit (solid line) to the (O) 0.01 M AOT (sample1) data with a poly disperse sphere form factor.

II-3(b) Non-linear least square fit (solid line) to the ( $\square$ ) $0.00125 \mathrm{M}$ lecithin/0.00875 M AOT (sample 2) data with a poly disperse sphere form factor

II-3(c) Non-linear least square fit (solid line) to the $(\Delta) 0.0025 \mathrm{M}$ lecithin/0.0075 M AOT (sample 3) data with a poly disperse sphere form factor

II-3(d) Non-linear least square fit (solid line) to the ( $(\boxplus)$ 0.00375M lecithin/0.00625M AOT (sample 4) data with a poly disperse sphere form factor and square well structure factor

II-3(e) Non-linear least square fit (solid line) to the $(\diamond) 0.005 \mathrm{M}$ lecithin/0.005 M AOT (sample 5) data with a poly disperse sphere form factor and square well structure factor

II-4(a) Non-linear least square fit (solid line) to the (O) 0.01 M AOT (sample1) data with an ellipsoid form factor.

II-4(b) Non-linear least square fit (solid line) to the ( $\square$ ) $0.00125 \mathrm{M}$ lecithin/0.00875 M AOT (sample 2) data with an ellipsoid form factor. 
lecithin/0.0075 M AOT (sample 3) data with an ellipsoid form factor.

II-4(d) Non-linear least square fit (solid line) to the ( $\boxplus$ ) $0.00375 \mathrm{M}$

lecithin/0.00625M AOT (sample 4) data with an ellipsoid form factor. Fit is done in an appropriate $\mathrm{q}$ region $\left(\mathrm{q}>0.018 \AA^{-1}\right)$ to obtain particle shape information only.

II-4(e) Non-linear least square fit (solid line) to the ( $(0) 0.005 \mathrm{M}$ lecithin/0.005 M AOT (sample 5) data with an ellipsoid form factor. Fit is done in an appropriate $\mathrm{q}$ region $\left(\mathrm{q}>0.018 \AA^{-1}\right)$ to obtain particle shape information only.

\section{CHAPTER III}

III-1 Log-Log plot of the Rayleigh ratio $\left(\mathrm{Rq}_{\mathrm{q}}\right)$ versus $\mathrm{q}$ for samples,

(O) 0.01MAOT (sample1), ( $\square$ ) $0.00125 \mathrm{M}$ Lecithin $10.00875 \mathrm{M}$ AOT (sample2), $(\Delta)$ 0.0025M Lecithin /0.0075M AOT (sample3), $(\boxplus)$ 0.00375M Lecithin $10.00625 \mathrm{M}$ AOT (sample4), and ( $\bullet$ ) 0.005M Lecithin /0.005M AOT (sample5). Sample1 and sample2 shows an asymptote at this $\mathrm{q}$ range indicative of Guinier region for the particle sizes in consideration. Sample 3, 4 and 5 shows an upturn (low q) indicative of large aggregates.

III-2 Straight-line fit (solid line) to the $\operatorname{Ln}(\mathrm{Rq})$ versus $\mathrm{q} 2$ data for samples, (O) 0.01MAOT (sample1) and ( $\square$ ) 0.00125M Lecithin 10.00875M AOT (sample2). Slope of the fit decreases from sample1 to sample2 indicates increase in the radius of gyration with increasing lecithin content in the system.

III-3(a) Cryo-TEM image showing vesicles (arrow heads) of sizes 20-300 60 $\mathrm{nm}$ in a thin vitrified film of the $24 \mathrm{mM}$ aqueous solution of cetyl trimethylammonium bromide (CTAB) and dodecyl benzene sulfonic acid (HDBS), mixed in a fixed ratio of 64:36 (CTAB:HDBS).

III-3(b) Cryo-TEM image showing micelles (arrow heads) of sizes 5-10 nm in a thin vitrified film of the system consisting of n-pentane, $n$ dodecane, octaethylene glycol dodecyl ether (C12 (EO) 8) and water, mixed in a fixed ratio of 1:1:2:22.67(by wt). 
III-4(a) Cryo-TEM image of 0.01M AOT system, showing a vitrified film of the sample.

III-4(b) Cryo-TEM image of $0.00125 \mathrm{M}$ Lecithin/0.00875M AOT system, showing a thin vitrified film of the sample

III-4(c) Cryo-TEM image of 0.0025M Lecithin/0.0075M AOT system, showing a vitrified film of the sample

III-4(d) Cryo-TEM image of $0.00375 \mathrm{M}$ Lecithin/0.00625M AOT system, showing a thin vitrified film of the sample

III-4(e) Cryo-TEM image of 0.005M Lecithin/0.005M AOT system, 66 showing a thin vitrified film of the sample.

\section{CHAPTER IV}

IV-1 Freeze fracture TEM image of the sample $(\mathrm{W} 0=170)$ at $40^{\circ} \mathrm{C}$, shows clear evidence of a lamellar microstructure.

IV-2 Specific heat capacity versus temperature data, using DSC, for sample $\left(W_{0}=130, \downarrow\right)$, for sample $\left(W_{0}=150, \|\right)$ and for sample $(W 0=170, \Delta)$. Experimental error hides out any detectable change in the heat capacity with temperature for all the samples. 


\section{CHAPTER I}

\section{I-1 Introduction:}

A microemulsion can be defined as a thermodynamically stable, transparent dispersion of two immiscible liquids, stabilized by an interfacial film of amphiphilic surfactant. Their microstructure varies from well defined spherical droplets or cylinders of one phase dispersed through out a bulk phase ${ }^{1}$ to intercontiguous networks ${ }^{2}$, or ordered/disordered bicontinous networks of both phases ${ }^{3}$.

In recent years, there has been a significant interest in the use of self assembled surfactant microstructures, as a templated media for the synthesis of novel materials. Mesoporous zeolites ${ }^{4}$, porous polymers ${ }^{5}$, biomimetic ceramics ${ }^{6}$, etc are just some of the fascinating examples of the materials that have been synthesized in the surfactant systems. The literature in this area is vast and there is tremendous potential in the development of materials for structural and device applications.

A much studied surfactant system for the synthesis of nanoclusters is the AOT water in oil microemulsion system. Here, the anionic surfactant, AOT (bis-2ethylhexyl sodium sulfosuccinate) (Figure I-1) stabilizes microaqueous droplets in a hydrocarbon phase. The water pools serve as microreactors for the synthesis of inorganic materials, and restrict particle growth to the nanoscale. The AOT water in oil microemulsion 
system has been used successfully in the synthesis of semiconductor quantum dots ${ }^{7}$ and super paramagnetic ferrites ${ }^{8}$ with novel optical and magnetic properties.

The work in this thesis is based on our finding of two-surfactant system, which demonstrates a novel transformation from a microemulsion to a rigid gel state. Specifically, we have found that the combination of zwitterionic surfactant phosphatidylcholine (lecithin) (Figure I-1) and AOT leads to a highly rigid gel (Figure I-1) that can sustain significantly high water content ${ }^{9}$. For example, when AOT and lecithin are dissolved in isooctane at concentrations of $0.8 \mathrm{M}$ and $0.4 \mathrm{M}$, respectively, the solution follows Newtonian behavior with a low viscosity of $0.1 \mathrm{~Pa}$.s. When water is added to the system, the viscosity increases, and the solution turns to a rigid gel phase when $\mathrm{W}_{0}=50-70\left(\mathrm{~W}_{0}\right.$ is defined as the molar ratio of water to AOT $)$. The gel stays rigid for $\mathrm{W}_{0}$ levels of up to 200 and typical zero shear viscosities over this range are on the order of $10^{6}$ Pa.s. ${ }^{9}$ Thus these surfactant gels may be sufficiently rigid to serve as templates for the synthesis of nanostructured materials, with the hypothesis, that the spatial immobilization of the hydrophilic and the hydrophobic regions would allow the formation of extended structures that are organized over multiple length scales.

In order to exploit these systems for templated material synthesis and also from the fundamental perspective of self-assembly in mixed surfactant systems, it is important to completely understand the microstructures involved in these systems. 
Numerous methods have been reported in literature for microstructure studies of complex fluids. A wide variety of techniques can be used to analyze the microstructures in self-assembled systems, including small angle neutron scattering (SANS), static and dynamic light scattering. All of these techniques involve modeling of the experimental data to determine particle shape and size. Imaging techniques like TEM, Cryo-TEM, SEM or Freeze fracture TEM provides high-resolution direct images. Thus the interpretation of data is model independent in this case. The excellent study on the microstructure of nonionic microemulsion using microscopy, neutron magnetic resonance (NMR), small angle X-ray scattering (SAXS) and small angle neutron scattering (SANS) reported by Regev et al. ${ }^{10}$ has been cited throughout this work.

The gel phase $\left(\mathrm{W}_{0}=70\right.$ onwards $)$ of these systems has already been characterized using small angle neutron scattering (SANS). ${ }^{11}$ As either the water content or temperature is varied, the microstructure undergoes a transition from columnar hexagonal to lamellar (Figure I-2). This change in curvature is only present in the mixed surfactant system at these overall concentrations. It was hypothesized that the different surfactant packing parameters, $P(P=v / a l$, where $v$ is the volume occupied by the tails, $a$ the effective head group cross-sectional area, and $l$ the maximum effective tail length), displayed by AOT $(P=1.1)$ and lecithin $(P=0.6)$ prompts a deformation of the spherical AOT reverse micelles as lecithin is added, producing structures of lower curvature. 
In this dissertation SANS, light scattering and cryogenic transmission electron microscopy have been done at low surfactant and low water content $\left(\mathrm{W}_{0}=20\right.$, total surfactant concentration in isooctane $=0.01 \mathrm{M}$ ). In order to reveal the respective roles of the two surfactants in determining the morphology of the water droplets, different ratios of lecithin to AOT $(0,1 / 3,1 / 7,3 / 5,1)$ were used.

Chapter II of this dissertation reveals the effect of two surfactants, on the droplet morphology, using small angle neutron scattering. Light scattering and cryogenic transmission electron microscopy (Cryo-TEM) studies on the similar system are reported in chapter III. . The idea is to combine these techniques together for a better understanding of the microstructure of the system under consideration.

An effort has also been made to further explore the gel system. Freeze fracture transmission electron microscopy and differential scanning calorimetery techniques were used and those results are reported in chapter IV. 


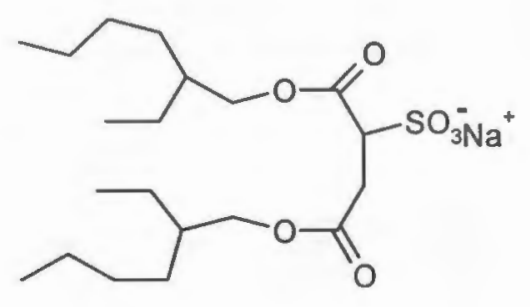

(a)

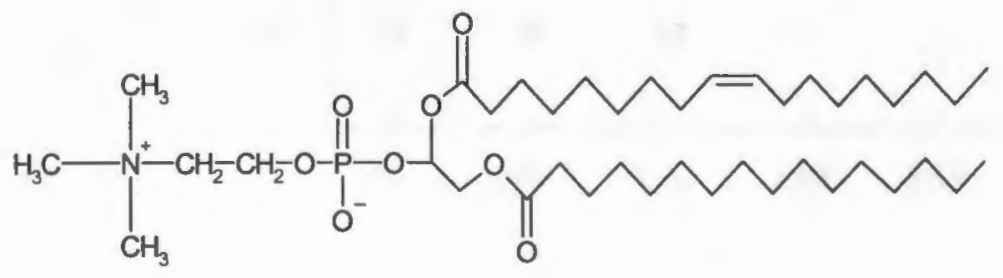

(c)

(b)

Figure I-1 (a) AOT molecule, (b) lecithin molecule, (c) rigid gel formed at $\mathrm{W}_{0}=90$ 


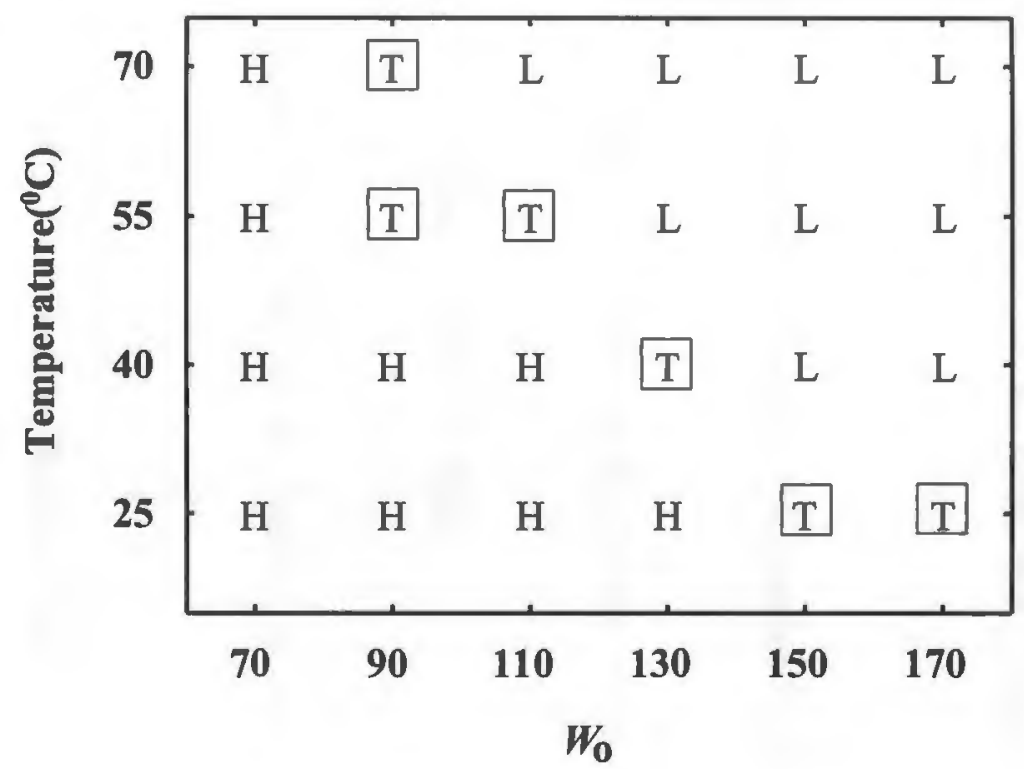

Figure I-2 Results of the SANS studies on the gel system. (H) represents hexagonal microstructure,

(L) represents lamellar microstructure and (T) represents the phase where both hexagonal and lamellar microstructure coexist. 


\section{References:}

' Lagues, M.; Ober, R.; Taupin, C. Journal of Physics Letters, 1978, 39, L-487.

${ }^{2}$ De Geyer, A.; Tabony, Journal of Chemical Physics Letters, 1985, 113, 83.

${ }^{3}$ Jouffray, J.; Levinson, P.; De Gennes, P.G. Journal of Physics, 1982, 43, 1241.

${ }^{4}$ Kresge, C.T.; Leonowicz, M.E.; Roth, W.J.; Vartuli, J.C.; Beck, J.S., Nature, 1994, 368,321 .

${ }^{5}$ Schmuhl, N.; Davis, E.; Cheung, H.M., Langmuir, 1998, 14, 757.

${ }^{6}$ Walsh, D.; Hopwood, J.D.; Mann, S., Science, 1994, 264, 1576.

${ }^{7}$ Pileni, M.P., Langmuir, 1997, 13, 3266.

${ }^{8}$ Lopez-Quintela, M.A.; Rivas, J., Journal of Colloid and Interface Science, 1993, $158,446$.

${ }^{9}$ Li, S.; Irvin, G.C.; Simmons, B.; Rachakonda, S.; Ramannair, P.; Banerjee, S.; John, V.T.; McPherson, G.L.; Zhou, W.; Bose, A. Colloids and Surfaces A, 2000, 174, 275.

${ }^{10}$ Regev, O.; Ezrahi, S.; Aserin, A.; Garti, N.; Wachetl, E.; Kaler, E. W.; Khan, A.; Talmon, Y. Langmuir, 1996, 12, 668. 
11 Simmons, B., Irvin, G. C., Li, S., John, V.T., McPherson, G.L., Balsara, N., Agarwal, V., Bose, A. Langmuir, 2002,18, 624-632. 


\section{CHAPTER II}

\section{SMALL ANGLE NEUTRON SCATTERING STUDIES ON A MIXED SURFACTANT MICROEMULSION SYSTEM}

\section{II-A Introduction}

Surfactants have the ability to self-assemble into a wide variety of supramolecular structures such as micelles, bilayers, vesicles, liquid crystals, and emulsions. ${ }^{1}$ Factors that determine the specific type of structure that is formed by a surfactant include the alkyl chain length, ${ }^{2}$ the nature of the solvent, surfactant concentration, ${ }^{3}$ temperature, salt concentration, ${ }^{4}$ and the presence of a co-surfactant. ${ }^{5}$

The additional compositional degree of freedom available in mixed surfactant solutions allows a wider range of aggregate structures and morphologies than is possible in single surfactant systems. For example, aqueous mixtures of cationic and anionic surfactants form a rich variety of composition-dependent microstructures in solution including spherical micelles, worm-like mixed micelles, vesicles, and lamellar phases. ${ }^{6}$ The expanded range of micellar geometries and functionalities available in mixed surfactant systems not only makes them useful for applications, but also provides opportunities for fundamental studies of self-assembly. Typical length scales for these micelles are of the order of several nanometers. Thus neutron scattering, where the probe wavelength is several angstroms, is a useful way to probe micellar structures. ${ }^{6,78}$ Additional advantages include the ability to selectively deuterate desired components in a mixture, thus allowing specific domains to be 
observed, and the insensitivity to dust. In the experiments reported here, the 'aqueous' phase is deuterium oxide $\left(\mathrm{D}_{2} \mathrm{O}\right)$.

Our interest lies in the micelles formed by mixing the anionic surfactant AOT and the zwitterionic phospholipid lecithin with water and isooctane. We have previously reported on the rigid mesophase formed when water is added to a solution containing $0.8 \mathrm{M}$ AOT and $0.4 \mathrm{M}$ lecithin in isooctane for $\mathrm{W}_{0}$ (molar ratio of water to AOT) values greater than $60 .^{9}$ The microstructure of this 'gel' has been characterized extensively via SANS. ${ }^{10}$ As either the water content or temperature is varied, the microstructure undergoes a transition from columnar hexagonal to lamellar. This change in curvature is only present in the mixed surfactant system at these overall concentrations. It was hypothesized that the different surfactant packing parameters, $P$ ( $P=v / a l$, where $\nu$ is the volume occupied by the tails, $a$ the effective head group cross-sectional area, and $l$ the maximum effective tail length), displayed by AOT ( $P=$ 1.1) and lecithin $(P=0.6)$ prompts a deformation of the spherical AOT reverse micelles as lecithin is added, producing structures of lower curvature.

Cadmium sulfide nanoparticles formed by precipitation in the AOT / lecithin / isooctane / aqueous solution microemulsion change shape from spherical to acicular as lecithin to AOT ratio in the microemulsion is increased from $0: 1$ to $1: 1 .^{11}$ This dramatic change in nanoparticle morphology is potentially a templating effect, produced by changes in droplet shape when lecithin is added to the system. In this paper, we look at mixtures of these surfactants formed at compositions just above the 
critical micelle concentration to uncover the role of lecithin on the configuration of the reverse micelles. By probing the effects of binary surfactant interactions on the resultant shape of the reverse micelles, a better understanding of self-assembly and microstructure may be obtained. From an applied perspective, these experiments may also help elucidate templating effects on nanoparticle synthesis.

\section{II-B Materials and methods}

\section{II-B1. Chemicals}

Lecithin (95\% pure, extracted from soybeans) was obtained from Avanti Polar Lipids, Inc. Bis (2-ethylhexyl) sodium sulfosuccinate (AOT) and 2,2,4trimethylpentane (isooctane - 99\% purity) were purchased from Sigma-Aldrich. Deuterium oxide (99.9\%) was purchased from Cambridge Isotopes Laboratory. All chemicals were used without further treatment or purification.

\section{II-B2. Sample preparation}

Five solutions were prepared. Each had an overall surfactant concentration of $0.01 \mathrm{M}$ in isooctane, but had different molar proportions of lecithin and AOT. The solution compositions were (1) $0.01 \mathrm{M}$ AOT with no lecithin, (2) $0.00875 \mathrm{M}$ AOT/0.00125 M lecithin, (3) $0.0075 \mathrm{M}$ AOT/0.0025 M lecithin, (4) $0.00625 \mathrm{M}$ AOT/0.00375 M lecithin, and (5) $0.005 \mathrm{M}$ AOT/0.005 M lecithin. Thus the molar ratios of lecithin to AOT were $0: 1,1: 7,1: 3,3: 5$ and 1:1 in samples 1 to 5 respectively. Reverse micellar solutions were obtained by adding the exact amount of $D_{2} \mathrm{O}$ necessary to bring the $W_{\mathrm{t}}=20\left(W_{\mathrm{t}}=\right.$ moles $\mathrm{D}_{2} \mathrm{O} /$ moles total surfactant). Since the 
total molar concentration of surfactant in isooctane does not vary, a fixed $W_{t}$ ensures that the fraction of water in each of the samples is also identical. Observed changes in scattering profiles can then be assigned only to variations in size and morphology of the deuterated water droplets, and interactions between them.

\section{II-B3. Experimental details}

Measurements were carried out on the $30 \mathrm{~m}$ NG3 beamline at the NIST Center for Neutron Research (Gaithersburg, MD). The instrument utilizes a mechanical velocity selector as a monochromator, a circular pinhole collimator, and a twodimensional position sensitive detector $\left(65 \times 65 \mathrm{~cm}^{2}\right)$. The SANS intensity, I, was recorded as a function of the scattering vector $q(=4 \pi \sin (\theta / 2) / \lambda$, where $\theta$ is the scattering angle and $\lambda$ the neutron wavelength). The neutron wavelength was $6 \AA$. The detector angle was set at $2^{\circ}$ and the sample-to-detector distance was set to $2 \mathrm{~m}$ and $13 \mathrm{~m}$ to cover the widest possible range of $q\left(0.004-0.6 \AA^{-1}\right)$. Samples were contained in closed stainless steel cells with quartz windows that provided a path length of 2 $\mathrm{mm}$. The sample temperature was maintained at $25^{\circ} \mathrm{C}$. The raw data was corrected for the scattering from an empty quartz cell, the detector sensitivity and background, the transmission of each sample, and placed on an absolute scale using software provided by NCNR. Since the major components of incoherent scatter are the spin contribution from hydrogen atoms and compositional contributions arising from differences in hydrogen and carbon cross-sections in isooctane, this number ${ }^{12}$ was subtracted from all our intensity data. 


\section{II-C Results and discussion}

A summary of all the compositions of the samples used in this study is presented in Table II-1. The corrected intensity data, I $(q)$, placed on an absolute scale, is presented in Figure II-1. They show the classical scattering profiles expected from micellar systems - a low $q$ asymptote (the Guinier region), followed by a drop (fractal region), and then a decay at large $q$. The immediately obvious differences in the scattering profiles as lecithin content is increased (although the total surfactant concentration and the sample water content stay constant) are (i) the systematic increase in the magnitude of the slope in the 'fractal' region $(0.05 \AA<\mathrm{q}<0.085 \AA)$ from $(-1.9)$ for sample 1 to $(-3)$ for sample 5 (ii) an upturn at low q for samples 4 and 5. Scattering from samples 2 and 3 overlap over the $q$ range explored here. Recently, we have used light scattering to examine the intensity profiles at lower values of $q$, and observe an upturn in intensity for sample 3 at $q \sim 0.002 \AA^{-1}$. This upturn is not seen in samples 1 and 2.

The scattering intensity obtained from an assembly of particles is given by ${ }^{13}$

$$
I(q)=N K_{i} P(q) S(q)=I(0) P(q) S(q)
$$

where $\mathrm{N}$ is the number of scattering centers, $K_{i}$ is the contrast factor resulting from radiation of type $i, P(q)$ is the intraparticle form factor describing scattering for a single particle, and $S(q)$ is the structure factor accounting for interparticle interactions. In dilute systems the intraparticle function $P(q)$ dominates the scattered intensity and $S(q)$ goes to unity, leading to 


$$
I(q)=N K_{i} P(q)=I(0) P(q)
$$

At low $q$, the scattering intensity from a dilute system of non-interacting particles is independent of morphology, and is given by

$$
\lim q \rightarrow 0, \frac{I(q)}{I(0)}=P(q)=\exp \left(\frac{-q^{2} R_{g}{ }^{2}}{3}\right)
$$

Here $R_{g}$ is the radius of gyration of the scattering objects. $R_{g}$ can be obtained from a plot of $\ln [\mathrm{I}(q)]$ versus $q^{2}$. For spheres of radius $R$, the radius of gyration, $R_{g}$, is given by

$$
R_{g}^{2}=\frac{3}{5} R^{2}
$$

Eq. II-4 needs to be modified if the spheres are polydispersed. For a Schultz size distribution of spheres ${ }^{14}$ with a mean particle radius $\bar{R}$ and a standard deviation $\sigma$, the scattering intensity as $q \rightarrow 0$ is given

$$
\lim _{q \rightarrow 0} \frac{I(q)}{I(0)}=\exp \left(\frac{-q^{2}\left\langle R^{2}\right\rangle}{5}\right)
$$

leading to the following expression for the radius of gyration

$$
R_{g}^{2}=\frac{3\left\langle R^{2}\right\rangle}{5}
$$

Here

$$
\left\langle R^{2}\right\rangle=\bar{R}^{2}+\sigma^{2}
$$


Figure II-2(a) shows a plot of $\ln (\mathrm{I}(q))$ versus $q^{2}$ for sample 1 , as well as a Guinier fit, using Eq. II-5 to fit the data. The radius of gyration, obtained from Eq. II6 is $31.3 \AA$. This procedure is repeated for samples 2 and 3. Samples 4 and 5 display upturns in intensity at low $q$ (for sample 3 this is observed in the light scattering data at $q \sim 0.002 \AA^{-1}$, not reported here. Samples 1 and 2 do not show this upturn in the $q$ space probed by light scattering). However, the length scale corresponding to the upturn is at least an order of magnitude larger than the droplet sizes, validating a Guinier fit for these samples in the appropriate region. All the radii of gyration produced this way are shown in Table II-3. As lecithin is added to the system there is a systematic increase in the radius of gyration of the water pools, from $R_{g}=31.3 \AA$ for sample 1 to $R_{g}=38.7 \AA$ for sample 5. Since the water content in each of the samples is identical, this increase in $R_{g}$ signifies an increase in the size of the droplets as lecithin is added.

Slopes in the fractal region of plots of $\log$ I versus $\log q$ vary between -1.9 to - 3. Thus the microemulsion droplets are likely to be polydispersed spheres. To provide further information on the morphology of the droplets, cross-section Guinier plots $^{15}$ of $\ln \left[\mathrm{I} \mathrm{q}^{\mathrm{x}}\right]$ versus $\mathrm{q}^{2}$ in the Guinier region $(0.003<\mathrm{q}<0.025)$ are shown in Figure II-2(a, b, c, d, e) for all the samples. The value of the exponent that makes this plot linear is an indicator of the morphology of the scattering objects. For all five samples, $\mathrm{x}=0$, providing further evidence that the droplets are spheres, and eliminating the possibility that the droplets are long rods $(x=1)$ or that the scattering is from lamellae $(x=2)$. 
Each of the I $(q)$ data sets were fitted using expressions for the form factors for polydispersed hard spheres, and shown in figure II-3(a, b, c, d, e). The mean sizes as well as the polydispersities (defined as the standard deviation $\sigma$ divided by the mean radius $\bar{R}$ ) are shown in Table II-2A. As the lecithin content is increased, the mean size goes up, while the polydispersity decreases. For water-in-oil microemulsions, the droplet radius as a function of water content is described by ${ }^{16}$

$$
\bar{R}\left[1+2(\sigma / \bar{R})^{2}\right] \approx(3 \mathrm{v} / a) \mathrm{W}_{\mathrm{t}},
$$

where $\mathrm{v}$ is the molecular volume of water and ' $a$ ' the average area/head group occupied by the surfactants at the interface. Table II-4 shows the values of ' $a$ ' calculated for our data using Eq. II-8 decreases systematically from $52.5\left(\AA^{2}\right)$ for sample 1 to $39\left(\AA^{2}\right)$ for sample 5 , indicating a more dense surfactant film and greater rigidity at the interface as the lecithin content is increased. The observed decrease in polydispersity is also a consequence of this increased rigidity at the isooctane/water interface.

The twin tailed anionic surfactant bis(2-ethylhexyl) sodium sulfosuccinate (AOT) typically forms spherical water-in-oil microemulsions. ${ }^{17}$ AOT has a surfactant packing parameter, $P$, of $1.1(P=v / a l$, where $v$ is the volume occupied by the tails, $a$ the effective head group area, and $l$ the maximum effective tail length), and tends to have a spontaneous curvature that is concave towards water. ${ }^{18,19}$ This causes AOT to 
spontaneously form spherical reverse micelles once above the critical micelle concentration. The zwitterionic surfactant phosphatidylcholine (lecithin) has a significantly larger head group and a smaller packing parameter of $0.6 .^{20}$ Thus lecithin would form structures of lower curvature than AOT. Indeed, in nonpolar solvents, lecithin forms wormlike cylindrical reverse micelles that can incorporate water up to a water/lecithin molar ratio of $20 .^{21}$ When both surfactants are present, the droplets grow as lecithin is added, reflecting this geometric packing effect.

The upturn in intensity at low $q$ for samples 4 and 5 (Figure II-1) is a signature of attractive interactions between the aqueous droplets. These interactions can give rise to formation of clusters, with a characteristic length $\mathrm{L} \sim 2 \pi / q_{u}$ where $q_{u}$ is the value of $q$ where the upturn begins. The length scale $L$ is of the order of $500 \AA$, much larger than the surfactant tail lengths. This dimension is an order of magnitude higher than that associated with the intermicellar attractive interactions in the AOT/water/near critical propane $e^{22}$ and in the water-in-carbon dioxide microemulsions near the critical point. ${ }^{23}$ The interaction potential $\mathrm{U}(r)$ between the droplets is modeled using a square well of the form

$$
\begin{array}{ll}
\mathrm{U}(\mathrm{r})=\infty & r<2 \bar{R} \\
\mathrm{U}(\mathrm{r})=-\varepsilon & 2 \bar{R} \leq r<2 \bar{R} \lambda \\
\mathrm{U}(\mathrm{r})=0 & r \geq 2 \bar{R} \lambda
\end{array}
$$

Here ' $r$ ' is the center-to-center distance between the droplets, $\bar{R}$ is an equivalent hard sphere radius ( $=$ radius of a sphere of volume equal to the droplet volume), $\varepsilon$ is the 
depth and $2 \bar{R}(\lambda-1)$ is the width of the square well. In this model, the well width provides an estimate of the largest distance over which interdroplet interactions are significant, while the well depth indicates the strength of the interaction. An analytical expression for the structure factor corresponding to this potential is available, and is used in Eq. II-1. The best-fit values of the width and depth of the square well are 538 $\AA$ and $0.022 \mathrm{kT}$ for sample 4 and $450 \AA$ and $0.126 \mathrm{kT}$ for sample 5. The most distinguishing feature in samples 4 and 5 is the extremely weak but rather long-range interactions between the droplets. Our interpretation is that the upturn reflects the formation of loosely bound clusters of droplets. The only potential impurities in our solutions are lipids of somewhat different molecular weight than lecithin $(95 \%$ pure lecithin is used in these experiments). These impurities are not likely to produce aggregates of length scale $\sim 50 \mathrm{~nm}$. Thus, we believe that impurities are an unlikely cause for the increase in scattering intensity observed at low values of $q$.

If each of the two surfactants distributes themselves locally on the interface in regions of preferred curvature, then the spherical AOT reverse micelles can be deformed into prolate ellipsoids as lecithin is added to the system. . Therefore, our SANS data was fitted to ellipsoid morphologies, and the fits are shown in Figure II$4(\mathrm{a}, \mathrm{b}, \mathrm{c}, \mathrm{d}, \mathrm{e})$ and the lengths of the major and minor axes resulting from these fits are reported in Table II-2B. The ratio of the major to minor axis changes from 2 for sample 1 to 1.5 for sample 5. The approach of this ratio towards 1 as the lecithin content is increased is consistent with the increased rigidity of the interface from samples 1 - 5. Since form factors for polydispersed spheres and prolate ellipsoids can 
be quite similar over the $q$ range examined here, it is not surprising that this alternate model also fits the data. The picture that develops then is either polydispersed spheres with $\mathrm{AOT} / \mathrm{lecithin}$ ratios varying between spheres, or ellipsoids where the AOT and lecithin occupy different regions of an ellipsoidal interface. On the basis of this SANS data alone, it is thus not possible to discriminate between these droplet morphologies.

The radius of gyration of an ellipsoid with principal axes radii ' $a$ ' and ' $b$ ', where ' $a$ ' is the radii of the rotation axis, is given by

$$
R_{g}^{2}=\left[\left(\frac{a}{5}\right)^{2}+2\left(\frac{b}{5}\right)^{2}\right]
$$

Using the morphology and size data from the fits, the calculated radii of gyration are compared to the measured $R_{g}$ in Table II-3. The maximum deviation is $10 \%$, pointing to the consistency in the model being applied.

We therefore summarize the interpretations to the scattering patterns in these dilute surfactant systems. With pure AOT as the surfactant, our observations are consistent with the literature that these are spherical droplets with a measure of polydispersity, and with negligible droplet-droplet interactions at these low concentrations. ${ }^{17}$ The partial substitution of lecithin for AOT, keeping overall concentration the same, leads to a larger size and greater interfacial rigidity. While we do not have direct evidence, there could also a deformation of the droplets to prolate ellipsoids. The tendency of AOT to occupy regions of higher curvature (about water) 
and the tendency of lecithin to form structures of lower curvatures, imply that the major axis of the ellipsoids with the higher curvatures regions being predominantly occupied by AOT, while lecithin may predominantly occupy the low curvature regions at the ends of the minor axis. The substitution of lecithin also leads to "sticky" droplets with very long-range interactions of the order of $50 \mathrm{~nm}$.

\section{II-D Conclusions}

Reverse micelles formed by a mixture of the anionic surfactant AOT and the zwitterionic surfactant lecithin to deuterated water / isooctane mixtures have been analyzed at various concentrations utilizing SANS. The key observations are an increase in droplet size, a drop in polydispersity and the development of an attractive interaction between the droplets as the lecithin concentration is increased. The AOT and lecithin have very different packing parameters. An alternate explanation for the observed scattering is that when both surfactants are present, each occupies regions of preferred curvature at the oil-water interface, leading to aspherical droplets. The weak attractive interaction over large length scales at high lecithin contents indicates the formation of loosely bound clusters.

We note a very interesting observation here. In the synthesis of CdS nanoparticles in these mixed surfactant systems at a higher overall surfactant concentration $(0.1 \mathrm{M})$, we have seen a dramatic change in particle morphology, from quantum dots in the pure AOT system, to highly acicular quantum rods in the 1:1 AOT:lecithin system. ${ }^{11}$ Additionally, the structure of these CdS crystallites changes 
from the face-centered cubic structure in the quantum dot morphology to the hexagonal structure in the quantum rod morphology. It is interesting to note that the length of these acicular particles is of the order of $50-100 \mathrm{~nm}$, while the width is 4-5 $\mathrm{nm}$. Perhaps the length extension of these quantum rods is a function of the interaction and cluster formation of the ellipsoidal droplets in the mixed surfactant system. Thus, it may be possible, by the use of mixed surfactants, to modify nanoparticle crystal structure and to template nanoparticle shape characteristics. 


\begin{tabular}{|c|c|c|c|}
\hline \hline Sample & $\begin{array}{c}\mathrm{W}_{\mathrm{t}}= \\
{\left[\mathrm{D}_{2} \mathrm{O}\right] /[\mathrm{SURF}]}\end{array}$ & $\begin{array}{c}\text { Total Surfactant } \\
\text { Concentration(M) }\end{array}$ & {$[$ lecithin]/[AOT] } \\
\hline 1 & 20 & 0.01 & $1 / 7$ \\
\hline 2 & 20 & 0.01 & $1 / 3$ \\
\hline 3 & 20 & 0.01 & $3 / 5$ \\
\hline 4 & 20 & 0.01 & 1 \\
\hline 5 & 20 & 0.01 & \\
\hline
\end{tabular}

Table: II-1 Compositions of all the components in the microemulsion, for all samples. 


\begin{tabular}{|c|c|c|c|c|}
\hline Sample & $\begin{array}{c}\text { Radius }(\AA) \\
\pm \\
\pm \\
\text { one standard } \\
\text { deviation }\end{array}$ & $\begin{array}{c}\text { Polydispersity } \\
\pm \\
\text { one standard } \\
\text { deviation }\end{array}$ & $\begin{array}{l}\text { Well Depth } \\
\text { (E/kT) } \\
\pm \\
\text { one standard } \\
\text { deviation }\end{array}$ & $\begin{array}{l}\text { Well Width } \\
\qquad(\AA) \\
\pm \\
\text { one standard } \\
\text { deviation }\end{array}$ \\
\hline 1 & $30.51 \pm 0.06$ & $0.26 \pm 0.00$ & NA & NA \\
\hline 2 & $36.05 \pm 0.14$ & $0.23 \pm 0.00$ & NA & NA \\
\hline 3 & $39.29 \pm 0.14$ & $0.19 \pm 0.00$ & NA & $\mathrm{NA}$ \\
\hline 4 & $42.56 \pm 0.19$ & $0.17 \pm 0.00$ & $0.022 \pm 0.00$ & $538 \pm 13.72$ \\
\hline 5 & $45.07 \pm 0.65$ & $0.14 \pm 0.01$ & $0.126 \pm 0.00$ & $450 \pm 6.03$ \\
\hline
\end{tabular}

Table: II-2A Results from the fit of polydisperse sphere form factor for samples 1,2 and 3 and polydisperse sphere form factor with square well structure factor for sample 4 and 5, to the SANS experimental data. 


\begin{tabular}{|c|c|c|c|}
\hline Sample & $\begin{array}{c}\text { Principal radius ' } a \text { ' }(\AA) \\
\text { (Rotation axis) }\end{array}$ & Principal radius ' $b$ ' $(\AA)$ & $a / b$ \\
\hline 1 & $63.0 \pm 1.0$ & $31.2 \pm 0.6$ & 2.0 \\
\hline 2 & $67.0 \pm 0.9$ & $36.8 \pm 0.5$ & 1.8 \\
\hline 3 & $65.7 \pm 1.0$ & $38.1 \pm 0.5$ & 1.7 \\
\hline 4 & $62.9 \pm 1.3$ & $41.5 \pm 0.6$ & 1.5 \\
\hline 5 & $63.2 \pm 1.1$ & $42.8 \pm 0.5$ & 1.5 \\
\hline
\end{tabular}

Table: II-2B Results from the fit of an ellipsoid form factor, in the appropriate q region for all the samples, to the experimental data 


\begin{tabular}{|c|c|c|c|}
\hline Sample & $\begin{array}{c}\text { Radius of gyration } \\
\text { from Guinier } \\
\text { approximation }(\AA)\end{array}$ & $\begin{array}{c}\text { Radius of gyration from } \\
\text { droplet dimensions }(\AA) \\
\text { (Polydisperse Spheres) }\end{array}$ & $\begin{array}{c}\text { Radius of gyration from } \\
\text { droplet dimensions }(\AA) \\
\text { (Prolate Ellipsoids) }\end{array}$ \\
\hline 1 & $31.3 \pm 0.2$ & 24.4 & 34.3 \\
\hline 2 & $35.7 \pm 0.2$ & 28.6 & 38.8 \\
\hline 3 & $36.2 \pm 0.2$ & 30.9 & 37.7 \\
\hline 4 & $37.3 \pm 0.1$ & 33.4 & 39.1 \\
\hline 5 & $38.7 \pm 0.2$ & 35.2 & \\
\hline
\end{tabular}

Table II-3 The radius of gyration obtained from a Guinier analysis and the radius of gyration calculated from the dimensions of the two different morphologies under consideration. 


\begin{tabular}{|c|c|}
\hline Sample & $\begin{array}{c}\text { ' } a \text { ' the average area/head group } \\
\left(\AA^{-2}\right)\end{array}$ \\
\hline 1 & 52.5 \\
\hline 2 & 44.4 \\
\hline 3 & 42.5 \\
\hline 4 & 40.2 \\
\hline 5 & 39.0 \\
\hline
\end{tabular}

Table II-4 ' $a$ ' the average area/head group calculated for the SANS data using Eq. II-8. ' $a$ ' decreases systematically from sample 1 to sample 5 indicating a more dense surfactant film and greater rigidity at the interface as the lecithin content is increased. 


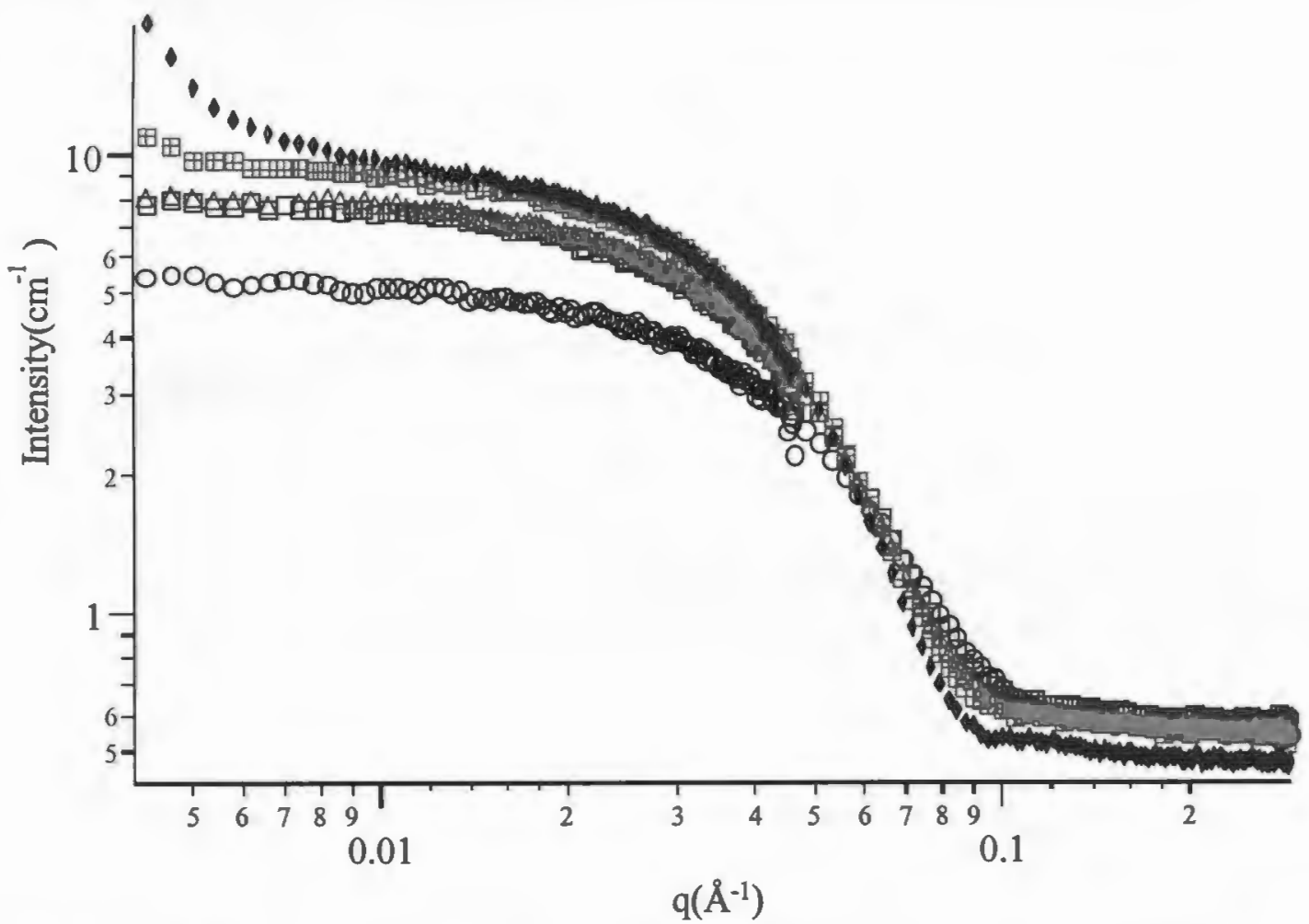

Figure II-1 Log-log plot of the intensity versus the magnitude of the scattering vector ' $q$ ' for samples, (O) 0.01MAOT, ( $\square$ ) 0.00125M Lecithin /0.00875M AOT, ( $\Delta$ ) 0.0025M Lecithin /0.0075M AOT,( $(\boxplus)$ $0.00375 \mathrm{M}$ Lecithin/0.00625M AOT, and $(\bullet) 0.005 \mathrm{M}$ Lecithin $/ 0.005 \mathrm{M}$ AOT. An obvious change in the scattering profiles can be found, (a) Upturn in low a q regime $\left(<0.01 \AA^{-1}\right)$ (b) Slope change in fractal regime $\left(0.04 \AA^{-1}<\mathrm{q}<0.09 \AA^{-1}\right)$, with increasing lecithin content in the system 


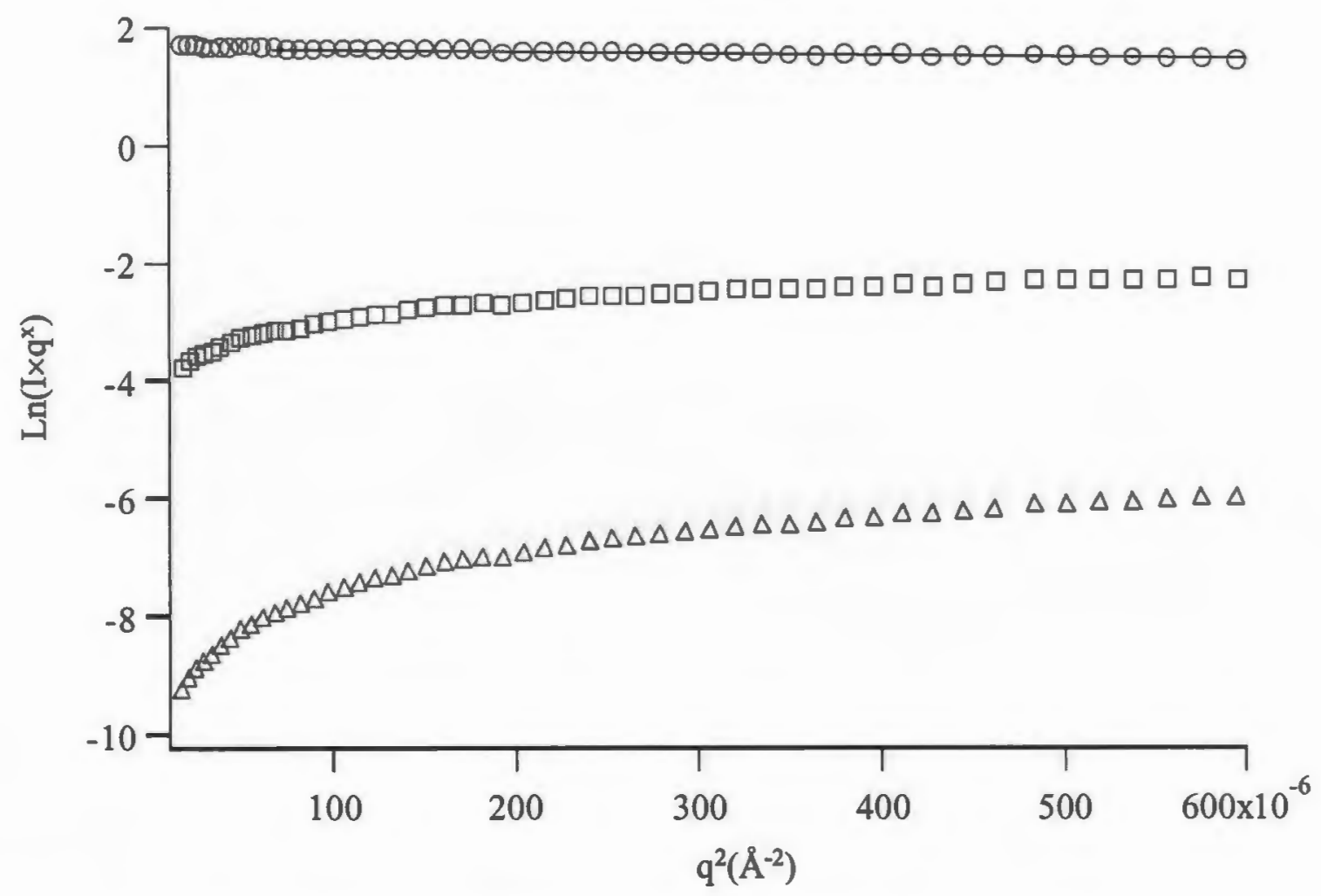

Figure II-2(a) Cross section Guinier plots for $0.01 \mathrm{M}$ AOT sample, $(O) x=0,(\square) x=1$, and $(\Delta) x=2$.

The solid line represents the straight line fit to the data. These data clearly suggests the potential morphologies of spheres rather than long cylinders or lamellar shapes. 


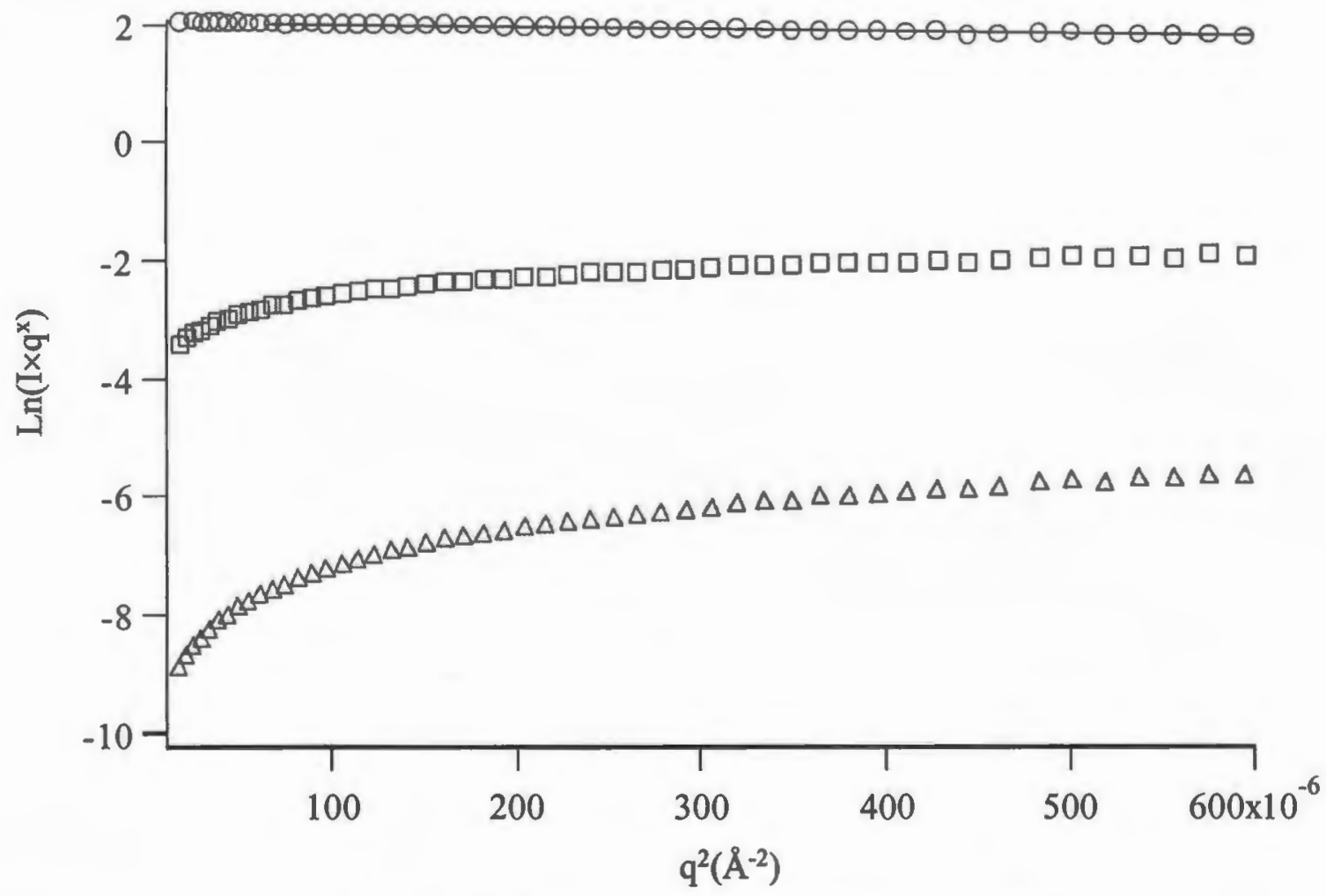

Figure II-2(b)Cross section Guinier plots for 0.00125M Lecithin/0.00875MAOT sample, $(\mathrm{O}) \mathrm{x}=0,(\square) \mathrm{x}=1$, and $(\Delta) x=2$. The solid line represents the straight line fit to the data. These data clearly suggests the potential morphologies of spheres rather than long cylinders or lamellar shapes. 


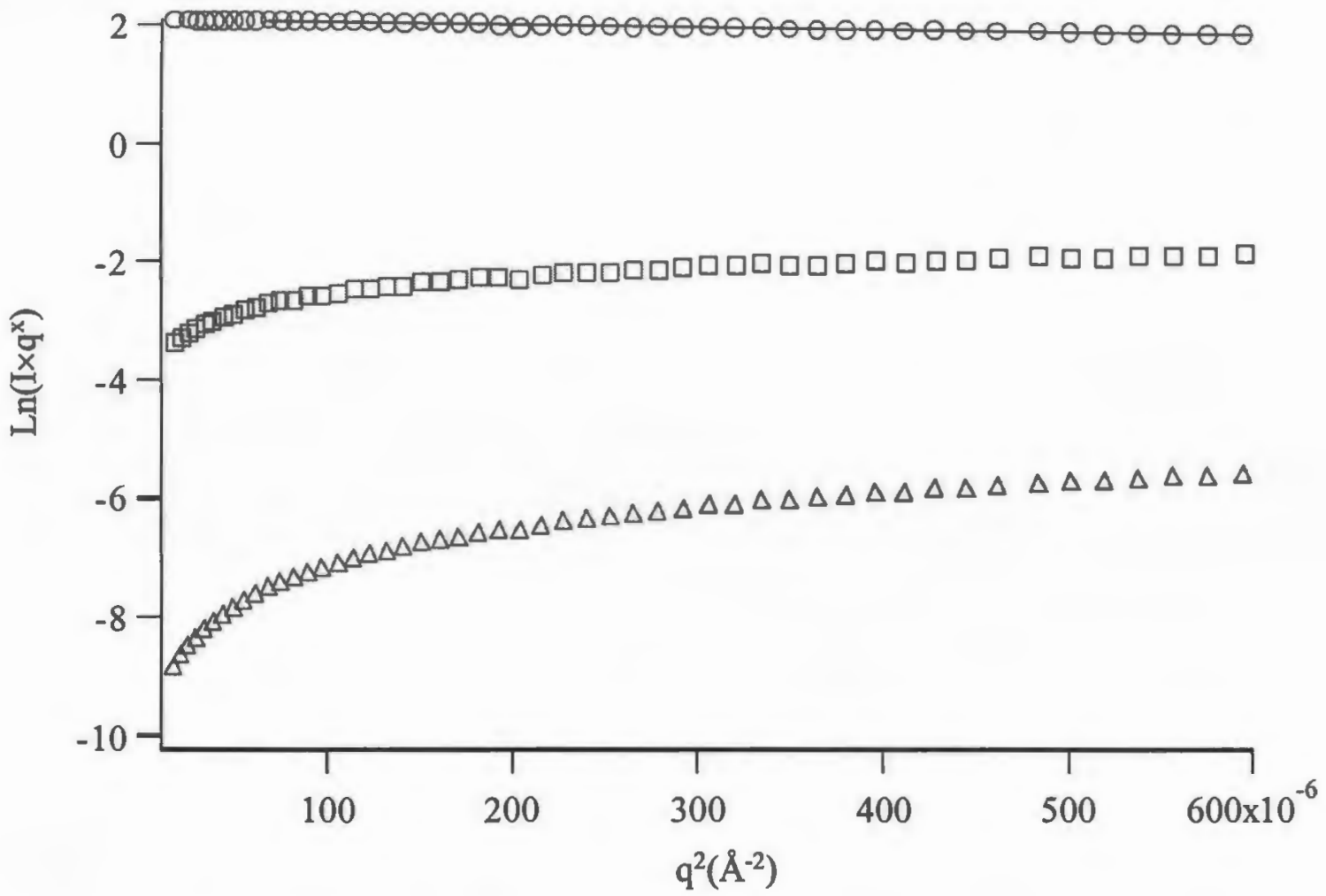

Figure II-2(c)Cross section Guinier plots for 0.00125M Lecithin/0.00875MAOT sample, $(0) x=0,(\square) x=1$, and $(\Delta) x=2$. The solid line represents the straight line fit to the data. These data clearly suggests the potential morphologies of spheres rather than long cylinders or lamellar shapes. 


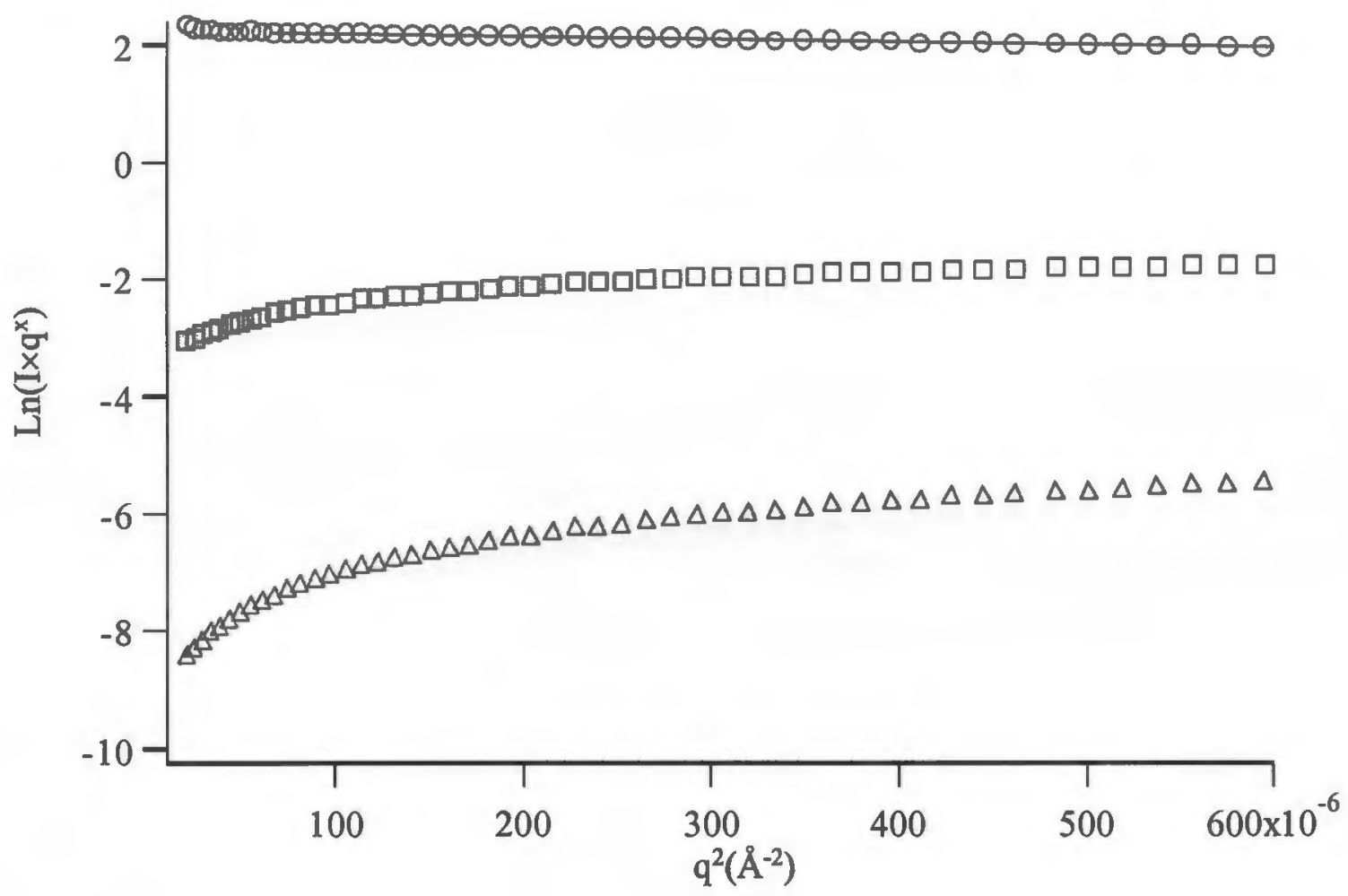

Figure II-2(d)Cross section Guinier plots for 0.00375M Lecithin/0.00625MAOT sample, $(0) x=0,(\square) x=1$, and $(\Delta) x=2$. The solid line represents the straight line fit to the data. These data clearly suggests the potential morphologies of spheres rather than long cylinders or lamellar shapes. 


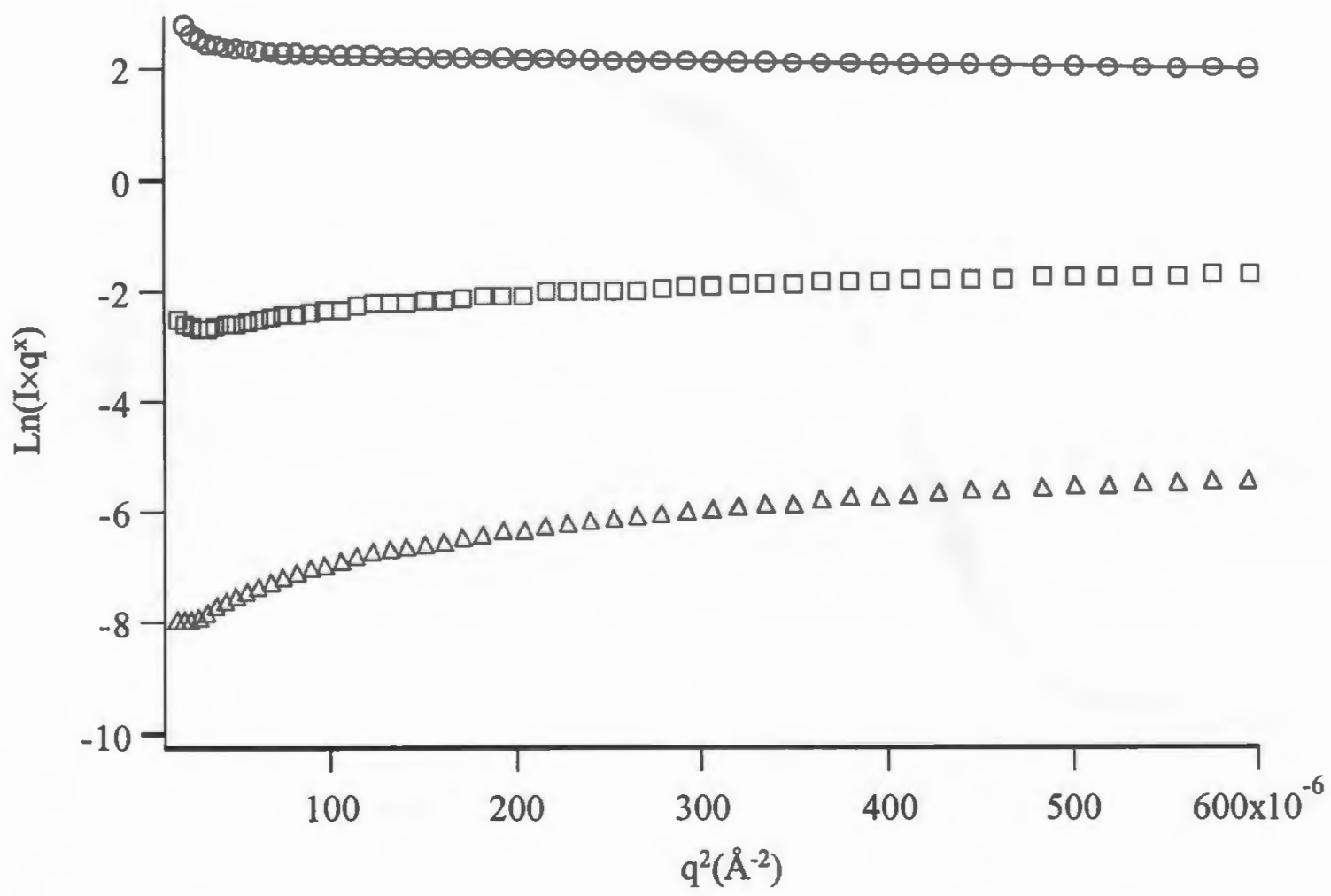

Figure II-2(e)Cross section Guinier plots for 0.005M Lecithin/0.005MAOT sample, $(O) x=0,(\square) x=1$, and $(\Delta) x=2$. The solid line represents the straight line fit to the data. These data clearly suggests the potential morphologies of spheres rather than long cylinders or lamellar shapes. 


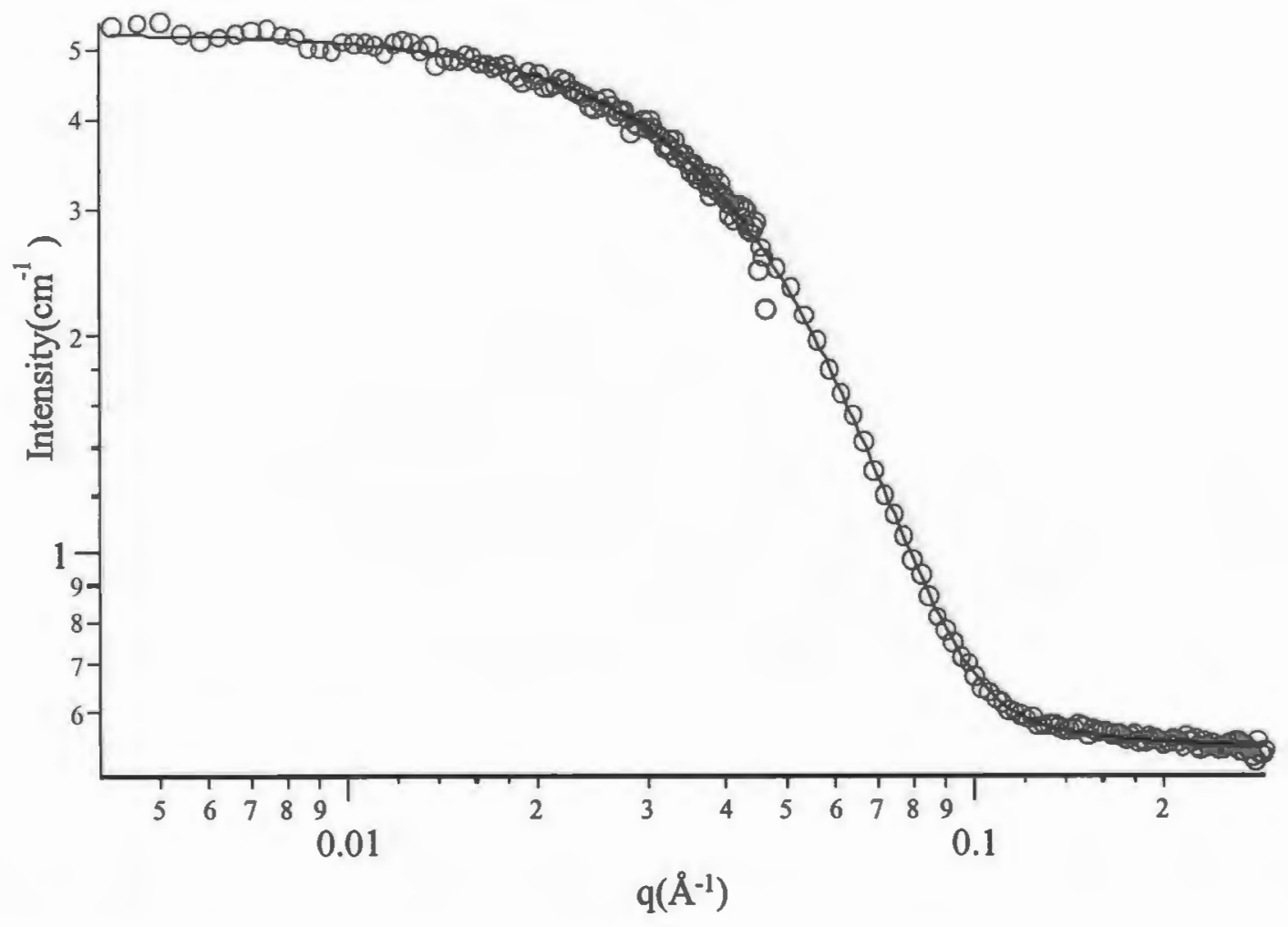

Figure II-3(a) Non linear least square fit (solid line) to the (O) $0.01 \mathrm{M}$ AOT (sample1) data with a poly disperse sphere form factor. 
$\stackrel{\omega}{\perp}$

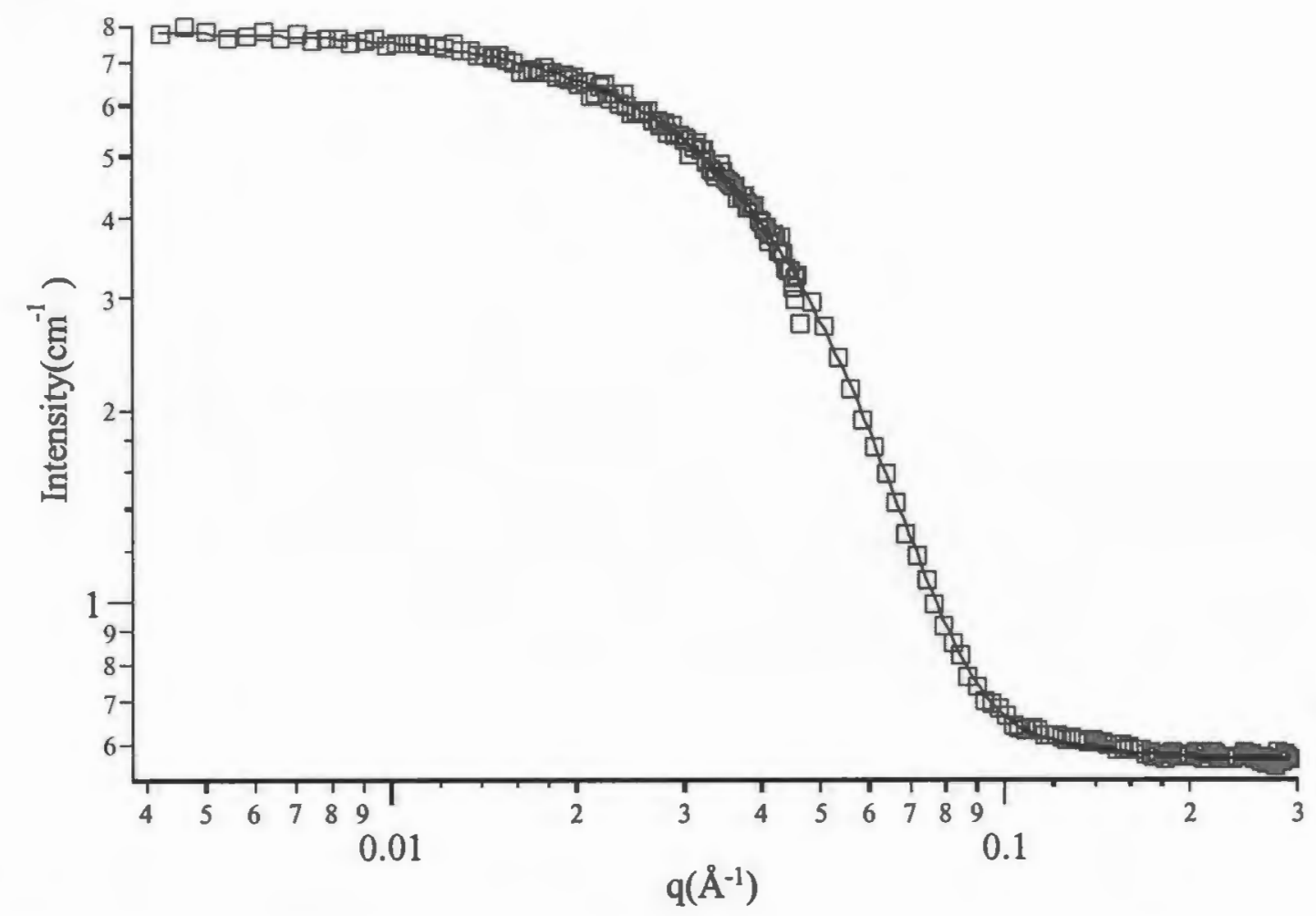

Figure II-3(b) Non linear least square fit (solid line) to the ( $\square$ ) $0.00125 \mathrm{M}$ lecithin/0.00875 M AOT(sample2) data with a poly disperse sphere form factor 


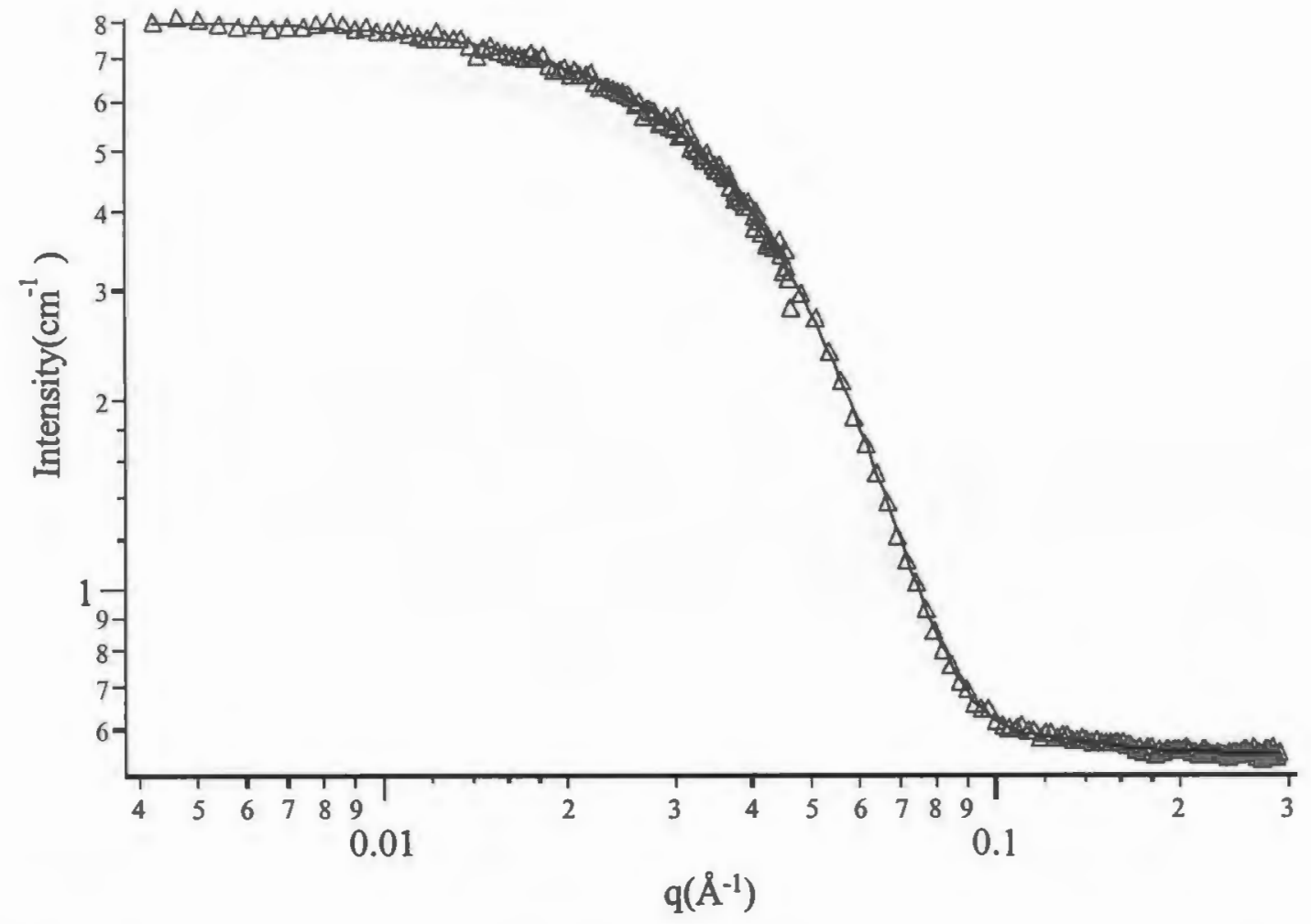

Figure II-3(c) Non linear least square fit (solid line) to the $(\Delta) 0.00250 \mathrm{M}$ lecithin/0.00750 M AOT(sample3) data with a poly disperse sphere form factor 


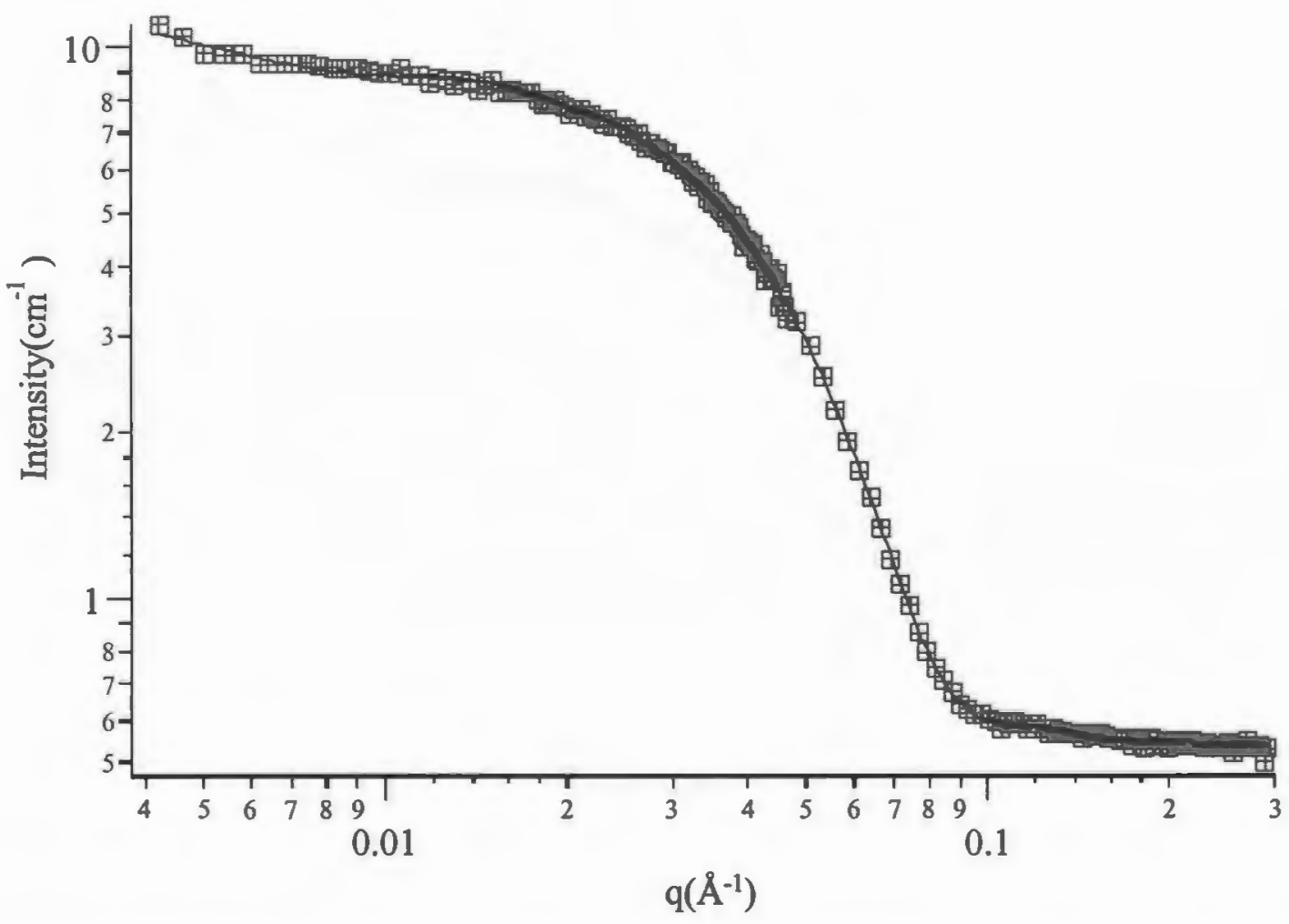

Figure II-3(d) Non linear least square fit (solid line) to the $(\boxplus)$ 0.00375 M lecithin/0.00625 M AOT(sample4) data with a poly disperse sphere form factor and square well structure factor 


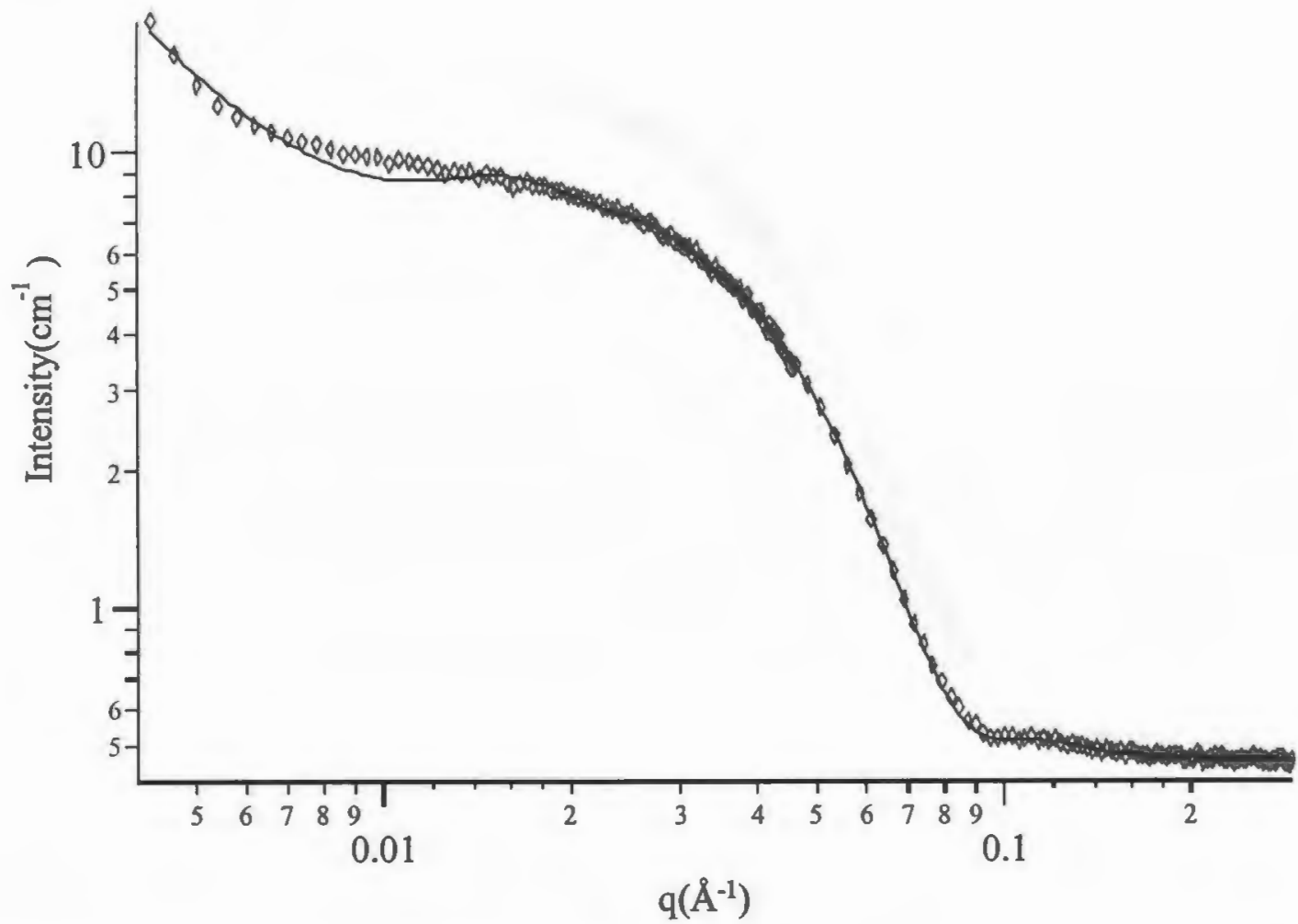

Figure II-3(e) Non linear least square fit (solid line) to the $(\diamond) 0.005 \mathrm{M}$ lecithin/0.005 M AOT(sample5) data with a poly disperse sphere form factor and square well structure factor 


$$
D
$$




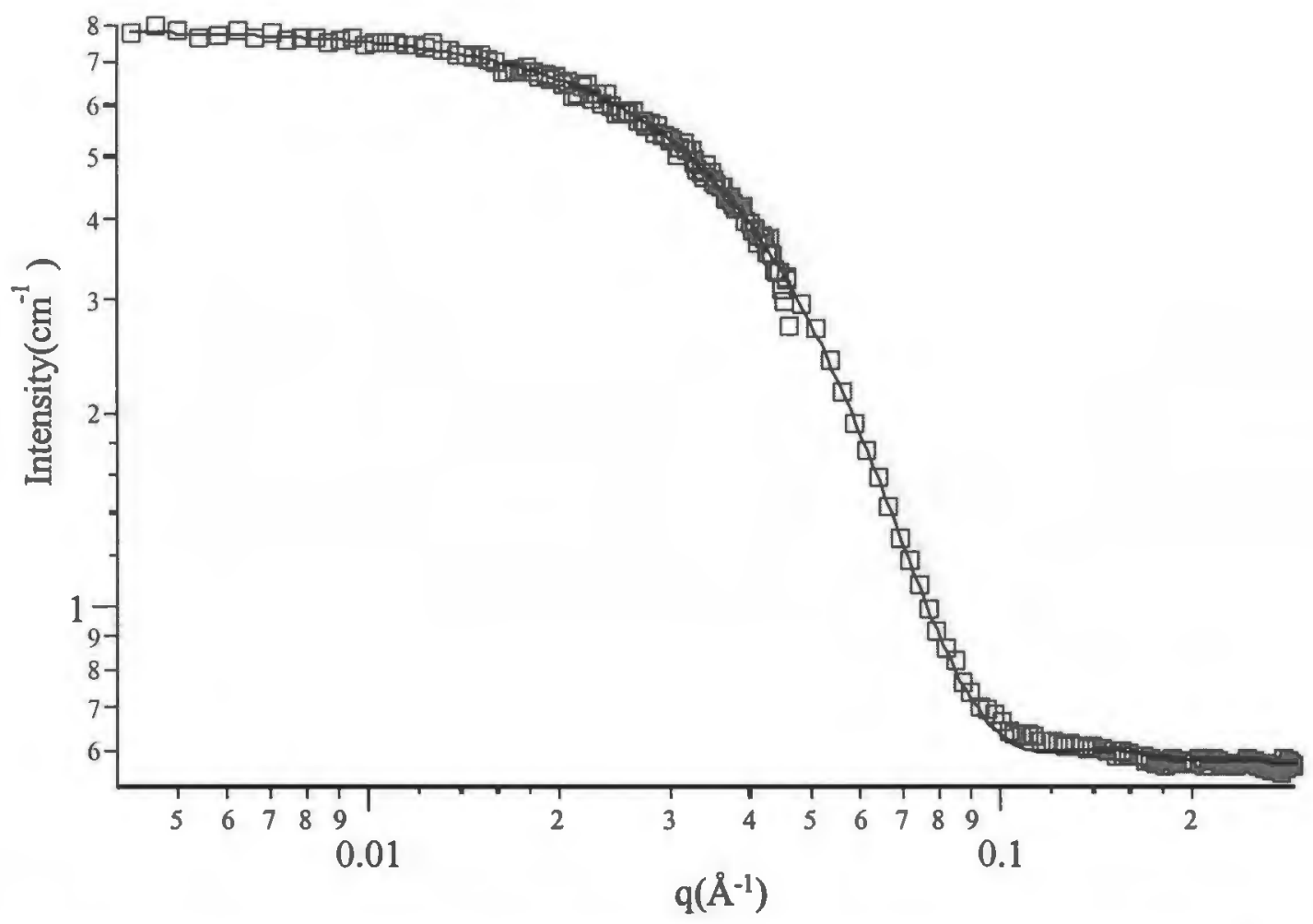

Figure II-4(b)Non linear least square fit (solid line) to the $(\square)$ 0.00125M Lecithin/0.00875M AOT (sample2) data with a ellipsoid form factor. 


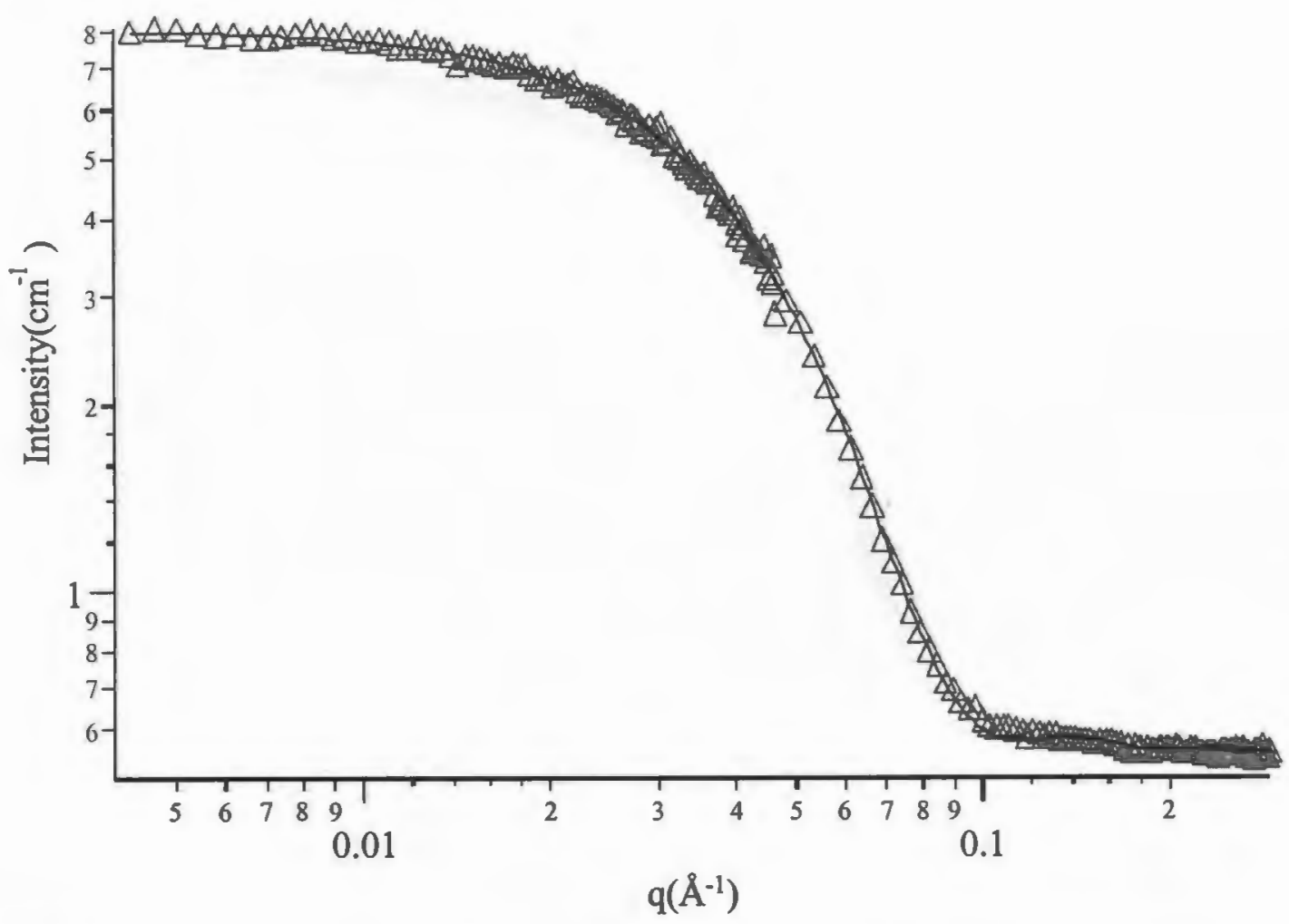

Figure II-4(c)Non linear least square fit (solid line) to the $(\Delta) 0.0025 \mathrm{M}$ Lecithin/0.0075M AOT (sample3) data with a ellipsoid form factor. 


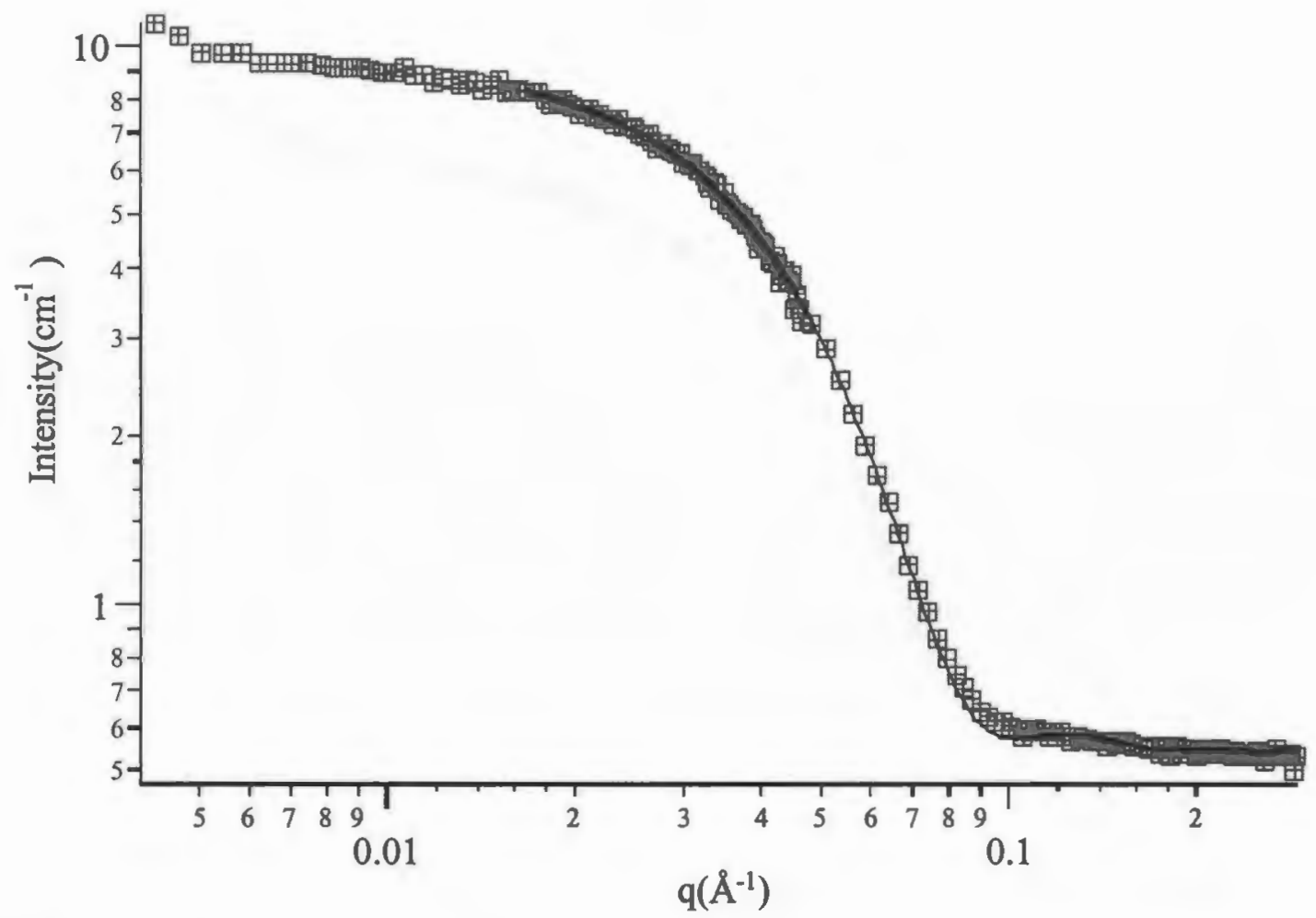

Figure II-4(d)Non linear least square fit (solid line) to the $(\boxplus)$ 0.00375M Lecithin/0.00625M AOT (sample4) data with a ellipsoid form factor. Fit is done in a appropriate q region(q $\left.>0.018 \AA^{-1}\right)$ to obtain particle shape information only. 


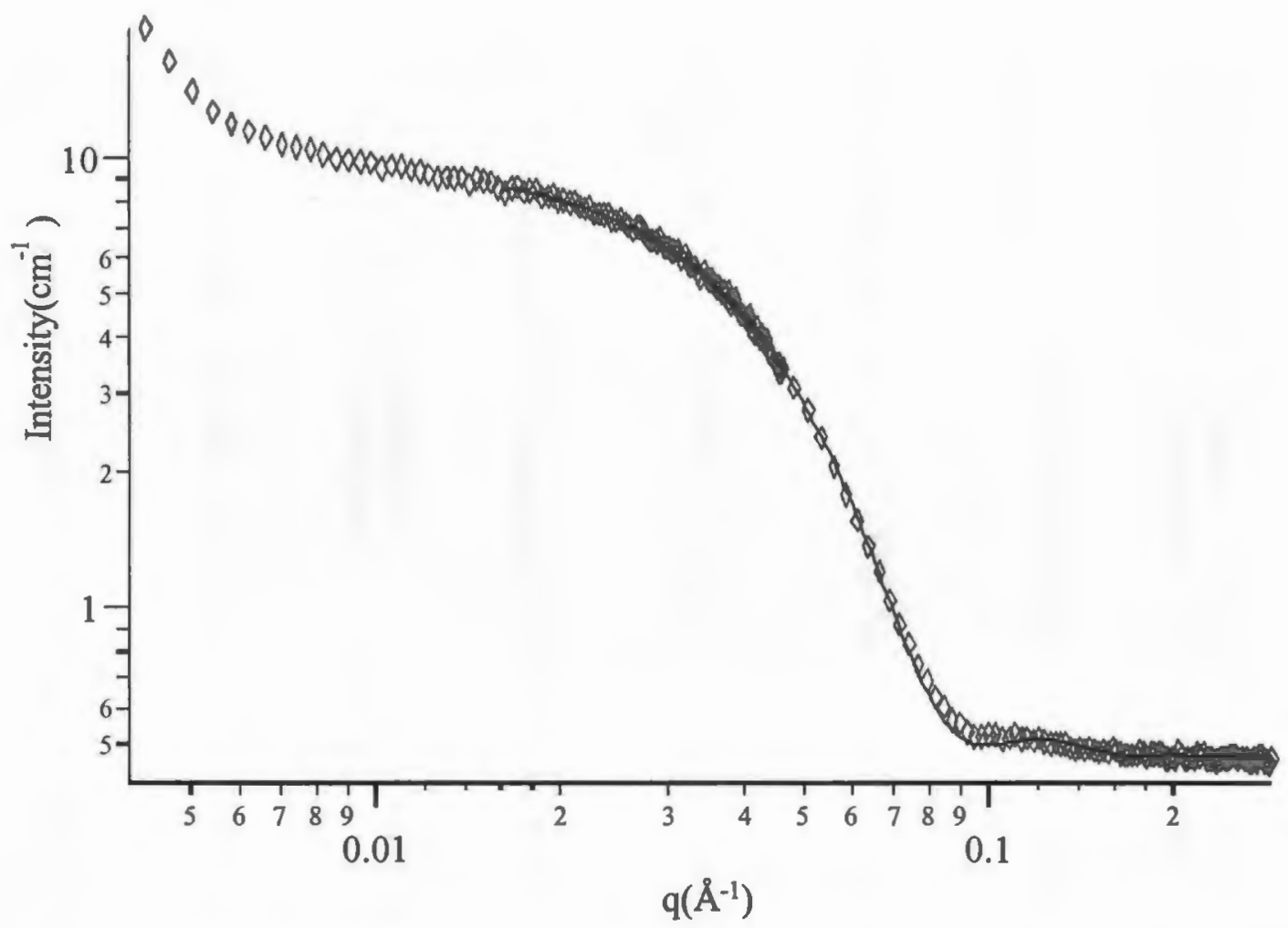

Figure II-4(e)Non linear least square fit (solid line) to the $(\diamond)$ 0.005M Lecithin/0.005M AOT (sample5) data with a ellipsoid form factor. Fit is done in a appropriate $q$ region $\left(q>0.018 \AA^{-1}\right)$ to obtain particle shape information only. 
References:

Imae, T. Colloid and Surface A, 1996, 109, 291-304.

2 Berlepsch, H. v.; Bottcher, C.; Ouart, A.; Regenbrecht, M.; Akari, S.; Keiderling, U.; Schnablegger, H.; Dahne, S.; Kirstein, S. Langmiur, 2000, 16, 5908-5916.

3 Koehler, R.D.; Raghavan, S.; Kaler, E.W. Journal of Physical Chemistry, 2000, $104,11025-11044$.

4 Kumar, S.; Aswal, V.K.; Goyal, P.S.; Din, K Journal of Chemical Society, 1998, 94(6), 761-764.

5 Freeman, K.S.; Tan, N.C.; Trevino, S.F.; Kline, S.; McGown, L.B.; Kiserow, D.J. Langmuir, 2001.

6 Bergstrom, M.; Pedersen, J.S.; Langmuir, 1998, 14, 3754-3761.

7 Bumajdad, A.; Eastoe, J.; Heenan, R.K.; Lu, J.R.; Steytler, D.C.; Egelhaaf, S. Journal of Chemical Society, 1998, 94 (15), 2143-2150.

8 Bergstrom, M.; Pedersen, J.S., Journal of Physical Chemistry B 2000, 104, 41554163.

9 S. Li, G. Irwin, B. Simmons, V. John, G. McPherson, A. Bose, Colloids and Surfaces $A, \underline{174}, 275$ (2000)

${ }^{10}$ Simmons, B., Irvin, G. C., Li, S., John, V.T., McPherson, G.L., Balsara, N., Agarwal, V., Bose, A. Langmuir, 2002,18, 624-632.

${ }^{11}$ Simmons, B., Li, S., John, V., McPherson, G., A. Bose, 2002, in press, Nanoletters 
12 Lise Arleth and Pedersen, J.S., Journal of Applied Crystallography 2000, 33, 650652.

13 A. Guinier and G. Fournet, Small Angle Scattering of X-rays (wiley-Interscience, NewYork), 1955

${ }^{14}$ Griffith, W. L.; Triolo, R.; Compere, A. L. Physical Review A, 1987, 35, 2200

15 O. Glatter et al.; Small Angle Scattering Applied to Microemulsions, Ber. Bunsenges. Phys. Chem. 100, 323-335 (1996) No. 3

${ }^{16}$ Kotlarchyk, M; Chen, S.H.; Huang, J.S.; Kim, M.W.; Phys. Rev. A 1984, 29, 2054 2069

17 Kotlarchyk, M.; Stephens, R.B.; Huang, J.S., Journal of Physical Chemistry 1988, 92, 1533.

18 Israelachvili, J.N. Intermolecular and Surface Forces, Academic Press, New York, 1992.

19 De, T.K.; Maitra, A., Advancement in Colloid and Interface Sciences 1995, 59, 193.

${ }^{20}$ Wabel, C., Ph.D. Dissertation, University of Erlangen, 1998.

${ }^{21}$ R. Scartazzini and P. L. Luisi, Journal of Physical Chemistry 1988, 92, 829.

D. Capitani, A.L. Segre, R. Sparapani, M. Giustini, R. Scartazzini, P.L. Luisi, Langmuir 1991, 7, 250.

Schurtenberger, P.; Scartazzini, R.; Luisi, P.L. Rheol. Acta. 1989, 28, 372. Luisi, P.L.; Scartazzini, R.; Haering, G.; Schurtenberger, P. Colloid and Polymer Science $1990,268,356$. 
22 Kaler, E. W., Billman, J. F., Fulton, J. L., Smith, R. D., Journal of Physical Chemistry 1991, 95, 461

23 C. T. Lee, Jr., K. P. Johnston, H. J. Dai, H. D. Cochran, Y. B. Melnichenko, G. D. Wignall, Journal of Physical Chemistry B 2001, 105, 3545 


\section{Chapter III}

\section{LIGHT SCATTERING AND CRYO TEM STUDY \\ OF MIXED AOT + LECITHIN REVERSE MICELLES \\ FORMED IN THE DILUTE REGIME}

\section{III-A Introduction}

Mixtures of surfactants, oil and water represents a prime example of self assembled systems, where the molecular interactions can lead to organization of surfactant molecules and the formation of a rich variety of structures such as microemulsions, vesicles and lamellar mesophases ${ }^{1}$.

Depending upon the composition of the system, a variety of different structures and phases are formed. The use of mixed surfactants to produce unique micellar geometries and thus functionality has been an area of active research over the past several years. The various geometries that these mixed surfactant systems cover represent a wide range of possibilities. Kaler et. al. found that mixtures of the oppositely charged surfactants cetyltrimethylammonium bromide (CTAB) and sodium octyl sulfate (SOS) form vesicles and micelles ${ }^{2}$. Rod-like micelles have been characterized by Thomas et. al. in the mixtures of the nonionic surfactants hexaethylene glycol monododecyl ether $\left(\mathrm{C}_{12} \mathrm{E}_{6}\right)$ and octaethylene glycol monododecyl ether $\left(\mathrm{C}_{12} \mathrm{E}_{8}\right)^{3}$. Imae et. al. observed elongated micelles formed by mixtures of the ionic surfactant alkyldimethylamine oxide $\left(\mathrm{C}_{n} \mathrm{DAO}\right)$ with the anionic surfactant sodium dodecylsulfate (SDS) ${ }^{4}$. 
A wide variety of techniques can be used to analyze the microstructures in these systems, including small angle neutron scattering (SANS), static and dynamic light scattering, which involves modeling of the experimental data to determine particle shape and size. Direct imaging techniques like TEM, Cryo-TEM, SEM or Freeze fracture TEM provides high-resolution direct images. Thus the interpretation of data is model independent in this case. Combining any two or three of these techniques gives independent information about the existing microstructure.

The four-component system consisting of anionic surfactant AOT and the zwitterionic phospholipid lecithin, water and isooctane is of primary interest in this work. The dilute surfactant $(0.01 \mathrm{M}$ total surfactant concentration in Isooctane) system formed by these two surfactants was already characterized via SANS. SANS profiles for different lecithin to AOT ratios $(0,1: 7,1: 3,3: 5$ and 1:1) are fitted well by a model containing polydispersed spheres. The mean size of the spheres increases, while the polydispersity decreases as the lecithin content is increased. For lecithin/AOT molar ratios of $3 / 5$ and 1 , the SANS profiles show an upturn at very low $q$ (where $q$ is defined as the scattering vector, $q=4 \pi \sin (\theta / 2) / \lambda$ with $\theta$ defined as the scattering angle and $\lambda$, is the neutron wavelength) values indicative of aggregate formation. In this chapter an attempt is made to explore these aggregates by using light scattering. Since the length scale probed by any scattering technique is $2 \pi / \mathrm{q}$, light scattering permits examination of morphologies of the order of $10-100 \mathrm{~nm}$. In addition, dynamic light 
scattering permits a direct examination of the diffusion coefficient and hence the hydrodynamic diameter of the scattering objects.

Transmission electron microscopy (TEM) is potentially one of the most useful techniques in the study of microstructured fluid system, providing direct images of the microstructure. The high vacuum in the microscope column, typically less than $10^{-4}$ $\mathrm{Pa}$, imposes a very strict limitation on the vapor pressure of the sample to be examined. It dictates that almost every fluid system to be examined requires pretreatment. Also, in these systems one typically finds rapid motion on the supramolecular scale, which needs to be arrested to prevent blurring of the image, as it is recorded by a slow scan CCD camera. The process of making the specimen satisfying the conditions of low vapor pressure and arrested motion is called 'fixation'. Fixation can be done either chemically (by addition of an alien chemical compound to the system, which selectively absorbs to certain part of the specimen, thus stabilizing them) or thermally (by ultra fast cooling of the liquid to a solid or a quasi solid state, at which its vapor pressure is extremely low and supra molecular motion is stopped). Most complex fluids are very sensitive to the chemical fixation so the only alternative is thermal fixation, which is also called direct imaging Cryo-TEM ${ }^{5}$. An attempt has been made to understand the microstructure in the low concentration mixed surfactant system with varying Lecithin/AOT ratios using Cryo-TEM as a direct imaging technique.

\section{III-B Experimental Section}




\section{III-B1 Chemicals}

95\% pure lecithin (extracted from soybeans) was obtained from Avanti Polar Lipids, Inc. Bis (2-ethylhexyl) sodium sulfosuccinate (AOT) and 2,2,4trimethylpentane (isooctane - 99\% purity) were purchased from Sigma-Aldrich. Distilled and deionized water was used. All chemicals were used without further treatment and/or purification.

\section{III-B2 Sample preparation}

Five stock solutions with differing molar ratios of AOT and lecithin were synthesized by adding the measured amount of either surfactant to a specific volume of isooctane and sonicating the mixture until a clear isotropic solution was obtained. The five stock solutions had AOT/lecithin molar compositions of (1) $0.01 \mathrm{M}$ AOT with no lecithin, (2) $0.00875 \mathrm{M}$ AOT/0.00125 M lecithin, (3) $0.0075 \mathrm{M}$ AOT/0.0025 $\mathrm{M}$ lecithin, (4) $0.00625 \mathrm{M}$ AOT/0.00375 $\mathrm{M}$ lecithin and (5) $0.005 \mathrm{M}$ AOT/0.005 M lecithin. Reverse micellar solutions were obtained by adding the exact amount of $\mathrm{H}_{2} \mathrm{O}$ necessary to bring the $W_{\mathrm{t}}=20\left(=\left[\mathrm{H}_{2} \mathrm{O}\right] /[\right.$ total surfactant $\left.]\right)$ for all of the samples analyzed. This ensures that for any combination of AOT and lecithin the water content remains constant as long as the total surfactant concentration remains constant as well.

\section{III-B3 Experimental details}

\section{III-B3.1 Static light scattering}

Samples were contained in a $26 \mathrm{~mm}$ outside diameter glass vials with Teflon stoppers. The vials were rinsed thoroughly in tap water followed by several rinses with 
filtered water and dried upside down in an oven in order to prevent dust from collecting inside the cell. All the samples were filtered several times using 0.22 micrometer filter to get rid off any dust contamination.

An argon ion laser from Brookhaven Instruments Corporation (BIC) was used for the light scattering measurements. The scattering intensity, I(q), was recorded as a function of the scattering vector $q(=4 \pi \sin (\theta / 2) / \lambda$ with $\theta$ defined as the scattering angle and $\lambda$ the laser wavelength). All data collection was carried out at $25^{\circ} \mathrm{C}$. The range of the q-values used for the static light scattering measurements was $0.0008 \AA$ to $0.003 \AA$.

\section{III-B3.2 Dynamic light scattering}

Dynamic light scattering arises from the fluctuations of the scattered light caused by the diffusion of particles (or clusters), assuming the particles (or clusters) to be rigid. The method of DLS makes use of the fact that the time dependence of these fluctuations can be related to the transitional diffusion coefficient of the particles. In order to quantitate this time dependence, the autocorrelation function of the scattered light intensity is measured, and from its time decay the correlation time (or times) of the intensity fluctuations is obtained. The precise estimations of average diffusion coefficient $\left(\mathrm{D}_{\mathrm{T}}\right)$ depend on the correlation time $\left(\tau_{\mathrm{c}}=1 / q^{2} \mathrm{D}_{\mathrm{T}}\right)$. Measurements were done at a wavelength of $514 \mathrm{~nm}$ and a scattering angle of $90^{\circ}$. 


\section{III-B3.3 Cryogenic transmission electron microscopy}

A few (2-3) microliters of a sample stored at $25{ }^{\circ} \mathrm{C}$ in a controlled environment vitrification system were withdrawn from a pipette, deposited on a lacey carbon electron microscope grid, and blotted to remove excess liquid. The grid bearing the sample was plunged into a liquid ethane reservoir cooled by liquid nitrogen to a temperature close to its freezing point. The rapid heat transfer away from the grid vitrified the sample. The specimen was transferred under liquid nitrogen to the cooled tip of a cryotransfer stage (Oxford CT3500), which was then inserted under positive dry nitrogen pressure into the JOEL 1200 TEM and imaged at slight underfocus. The sample temperature was maintained at $-165^{\circ} \mathrm{C}$ at all times during imaging to prevent any transformation from amorphous to crystalline phase in isooctane.

\section{III-C Analysis}

\section{III-C1 Light scattering}

To obtain a value from the measured intensity that depends only on the property of the scatterer and not on the source or the detector optics we used the Rayleigh ratio which is defined as follows,

$$
R_{\theta}=R_{c}\left(90^{\circ}\right) \cdot \sin (\theta) \cdot\left(I_{\theta} / I_{c}\right)
$$


where $I_{\theta}$ (=time averaged solution intensity - time averaged solvent intensity), $I_{c}$ is the time averaged toluene intensity at $90^{\circ}, \theta$ is the scattering angle and $R_{c}\left(90^{\circ}\right)$ is the Rayleigh ratio of toluene at $90^{0}\left(=32 \times 10^{-6} \mathrm{~cm}^{-1}\right)$.

Using the Guinier approximation, at low $q$ the scattering intensity $R(q)$ is given by,

$$
R_{\theta}(q)=\exp \left(\frac{-q^{2} R_{g}{ }^{2}}{3}\right)
$$

where $R_{g}$ is defined as the radius of gyration of the particle.

We can therefore extract a value for $R_{\mathrm{g}}$ by plotting $\ln R_{\theta}(\mathrm{q})$ versus $\mathrm{q}^{2}$ and measuring the slope of the line that best fits the data. If the micelles are spherical, the radius $R$, is given by the equation

$$
R_{g}^{2}=\frac{3}{5} R^{2}
$$

The DLS experimental data was analyzed using a multiple pass non-negatively constrained least squares analysis. The mean hydrodynamic radius $\left(R_{h}\right)$ was calculated from $\mathrm{D}_{\mathrm{T}}$ using the Stokes-Einstein relation for spherical particles.

$$
R_{h}=\frac{k_{B} T}{6 \pi \eta D_{T}}
$$


where $\eta$ is the viscosity of the sample solution, $T$ is the temperature of the sample solution, $\mathrm{k}_{\mathrm{B}}$ is the Boltzmann constant, $1.38 \times 10^{-23} \mathrm{~K}^{-1}$ and $\mathrm{D}_{\mathrm{T}}$ the experimentally obtained diffusion coefficient.

\section{III-C2 Cryogenic transmission electron microscopy}

Two different systems were analyzed as the control. Vesicles formed in a $24 \mathrm{mM}$ aqueous solution of cetyl trimethylammonium bromide (CTAB) and dodecyl benzene sulfonic acid (HDBS), mixed in a fixed ratio of 64:36 (CTAB:HDBS) ${ }^{6}$ were used as the first control to insure the proper working of the Cryo-TEM facility. Micellization in a system consisting of n-pentane, n-dodecane, octaethylene glycol dodecyl ether $\left(\mathrm{C}_{12}(\mathrm{EO})_{8}\right)$ and water, mixed in a fixed ratio of 1:1:2:22.67(by wt), which is an oil (dispersed phase) in water (continuous phase) microemulsion system, was used as the second control in order to make sure the feasibility of imaging micelles of sizes $5-20 \mathrm{~nm}$.

\section{III-D Results and discussion}

Mean hydrodynamic radii of all the five samples, determined by the dynamic light scattering measurements, are reported in Table III-1. With the exception of a decrease in the mean hydrodynamic radii from pure AOT system to $0.00125 \mathrm{M}$ Lecihtin/0.00875M AOT system, the general trend shows an increase in the mean hydrodynamic radius with increasing lecithin content in the system. 
The static light scattering profiles (Figure III-1) combined with the knowledge of the mean hydrodynamic radius for all the samples indicates the profiles for the $0.01 \mathrm{M}$ AOT system and $0.00125 \mathrm{M}$ lecithin/0.00875M AOT system represents a low $\mathrm{q}$ asymptote (Guinier region) of the scattering profile for these systems. Similarly the upturn in the scattering profile of the $0.0025 \mathrm{M}$ lecithin/0.0075M AOT, $0.0025 \mathrm{M}$ lecithin/0.0075M AOT and $0.0025 \mathrm{M}$ lecithin/0.0075M AOT systems at such a low $\mathrm{q}$, indicates the presence of long range interactions between the particles, which can also be visualize as the presence of large aggregates. Due to the limited amount of the scattering data (limited q-range), the size information about these aggregates cannot be extracted.

Guinier analysis was done on the scattering profiles of $0.01 \mathrm{M}$ AOT sample and $0.00125 \mathrm{M}$ lecithin/0.00875M AOT sample (Figure III-2). The resulting radius of gyration $\left(\mathbf{R}_{\mathrm{g}}\right)$ is tabulated in Table III-1. The radius of gyration calculated using (Eq. III-3) from the mean hydrodynamic radius for $0.01 \mathrm{M}$ AOT system $(\sim 35 \AA)$ is in close match with the radius of gyration calculated from the Guinier analysis $(\sim 38 \AA)$ indicative of the spherical morphology in the pure AOT system.

The Cryo-TEM image (Figure III-3A) of a vitrified thin film of the $24 \mathrm{mM}$ aqueous solution of cetyl trimethylammonium bromide (CTAB) and dodecyl benzene sulfonic acid (HDBS), mixed in a fixed ratio of 64:36 (CTAB: HDBS) clearly showing the vesicles of the sizes $30 \sim 200 \mathrm{~nm}$, insures the proper working of the CryoTEM facility. 
The other Cryo-TEM image (Figure III-3B) of a vitrified thin film of the sample consisting of n-pentane, n-dodecane, octaethylene glycol dodecyl ether $\left(\mathrm{C}_{12}(\mathrm{EO})_{8}\right)$ and water, mixed in a fixed ratio of 1:1:2:22.67(by wt) showing individual micelles of size $5 \sim 10 \mathrm{~nm}$ provides a very good reference for the analysis of the microemulsion samples keeping in mind that we have water (dispersed phase) in oil (continuous phase) microemulsion system.

The Cryo-TEM images for all the samples (Figure III-4 A, B, C, D, E) do not provide adequate structural information about the system. That puts a question mark on the Cryo-TEM procedure in order to image organic rich samples. We recently found that liquid ethane (used in the freezing process) dissolves hydrocarbons, potentially explaining why we did not get any structural information from our experiments. A next step to improve our Cryo-TEM analysis would be to change the Cryo fluid (for rapid cooling) from liquid ethane to liquid nitrogen in order to stabilize hydrocarbon matrix. These experiments are currently underway.

\section{III-E Conclusions}

Light scattering studies on the reverse micelles formed by a mixture of the anionic surfactant AOT and the zwitterionic lecithin are in accord with all the findings from the SANS analysis. The differences in the calculated radius of gyration from a Guinier region analysis for both techniques accounted for the differences in probing the water core in case of SANS versus probing the whole particle (water core + 
surfactant layer) in case of light scattering. The presence of the low q upturn in the scattering intensity for $(0.0075 \mathrm{M}) \mathrm{AOT} /(0.0025 \mathrm{M})$ lecithin sample indicates the presence of the long-range attractive interactions between the particles even at the low lecithin content. Cryo-TEM with liquid nitrogen as a freezing medium might be able to produce meaningful images for oil rich systems. 


\begin{tabular}{|c|c|c|c|}
\hline Sample & $\begin{array}{c}\text { Mean Hydrodynamic } \\
\text { Radius }(\AA) \\
\text { (Approx.) }\end{array}$ & $\begin{array}{c}\text { Radius of gyration } \\
\text { from Guinier } \\
\text { approximation }(\AA)\end{array}$ & $\begin{array}{c}\text { Radius of gyration } \\
\text { from droplet } \\
\text { dimensions }(\AA) \\
\text { (Assuming spheres) }\end{array}$ \\
\hline 1 & 45 & $38 \pm 1.1$ & 35 \\
\hline 2 & 35 & $41 \pm 1.3$ & 27 \\
\hline 3 & 40 & NA & 31 \\
\hline 4 & 50 & NA & 39 \\
\hline 5 & 60 & NA & 47 \\
\hline
\end{tabular}

Table III-1 Results from the experimental data for all the five samples. Column 2 contains the hydrodynamic radii information from dynamic light scattering experiments. Column 3 reports the radius of gyration obtained from the Guinier analysis of the static light scattering data. Column 4 reports the calculated radius of gyration (using Eq.III-3) based on the hydrodynamic radius tabulated in column2 


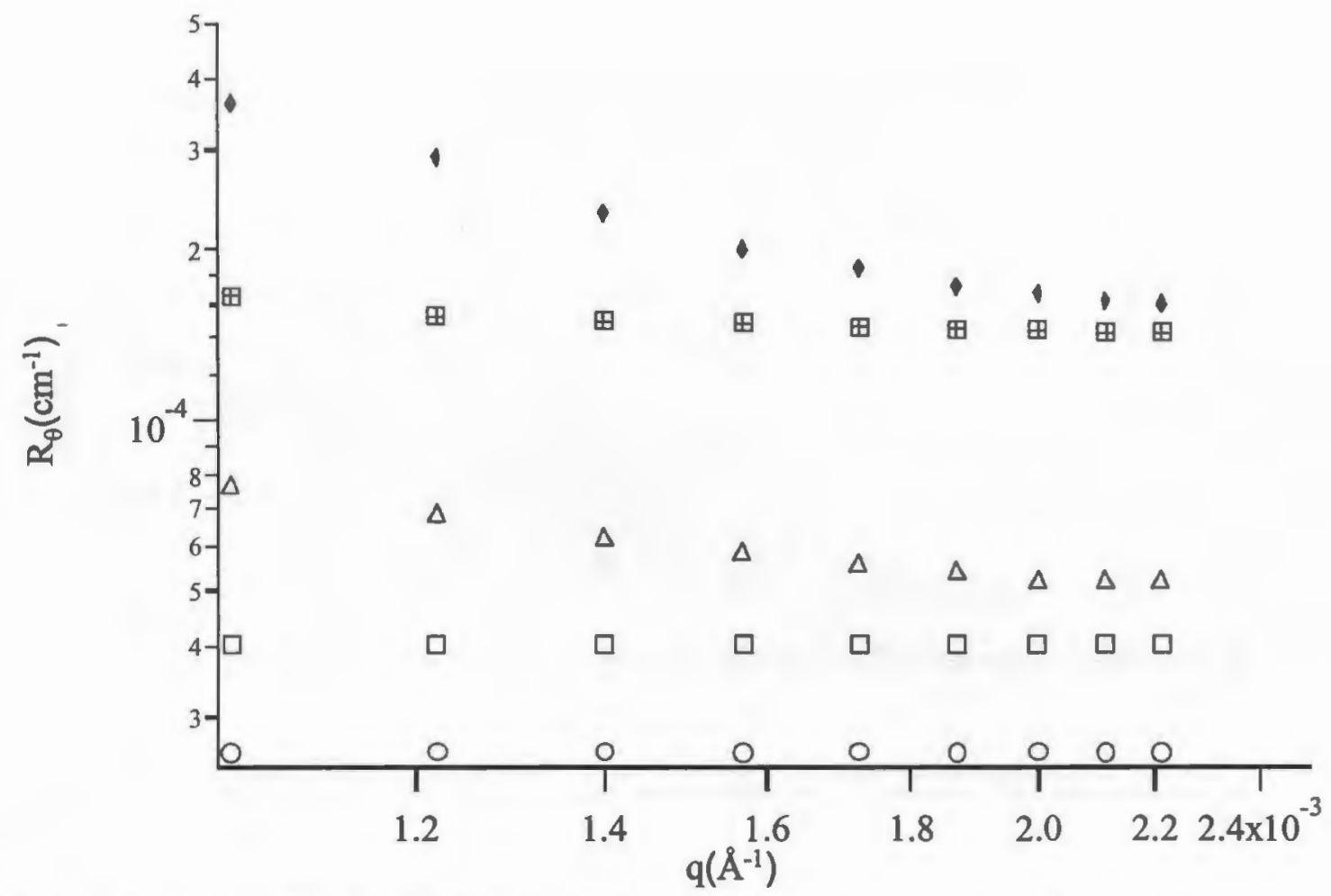

Figure III-1 Log-log plot of the Rayleigh ratio $\left(R_{\theta}\right)$ versus q for samples, (O) 0.01MAOT(sample1), ( $\square$ ) $0.00125 \mathrm{M}$ Lecithin/0.00875M AOT (sample2), ( $\Delta$ ) 0.0025M Lecithin /0.0075M AOT (sample3), (田) 0.00375M Lecithin/0.00625M AOT (sample4), and ( $\bullet$ ) 0.005M Lecithin /0.005M AOT (sample5). Sample1 and sample2 show an asymptote at this $q$ range indicative of Guinier region for the particle sizes in consideration. Sample 3,4 and 5 shows an upturn(low q) indicative of large aggregates. 


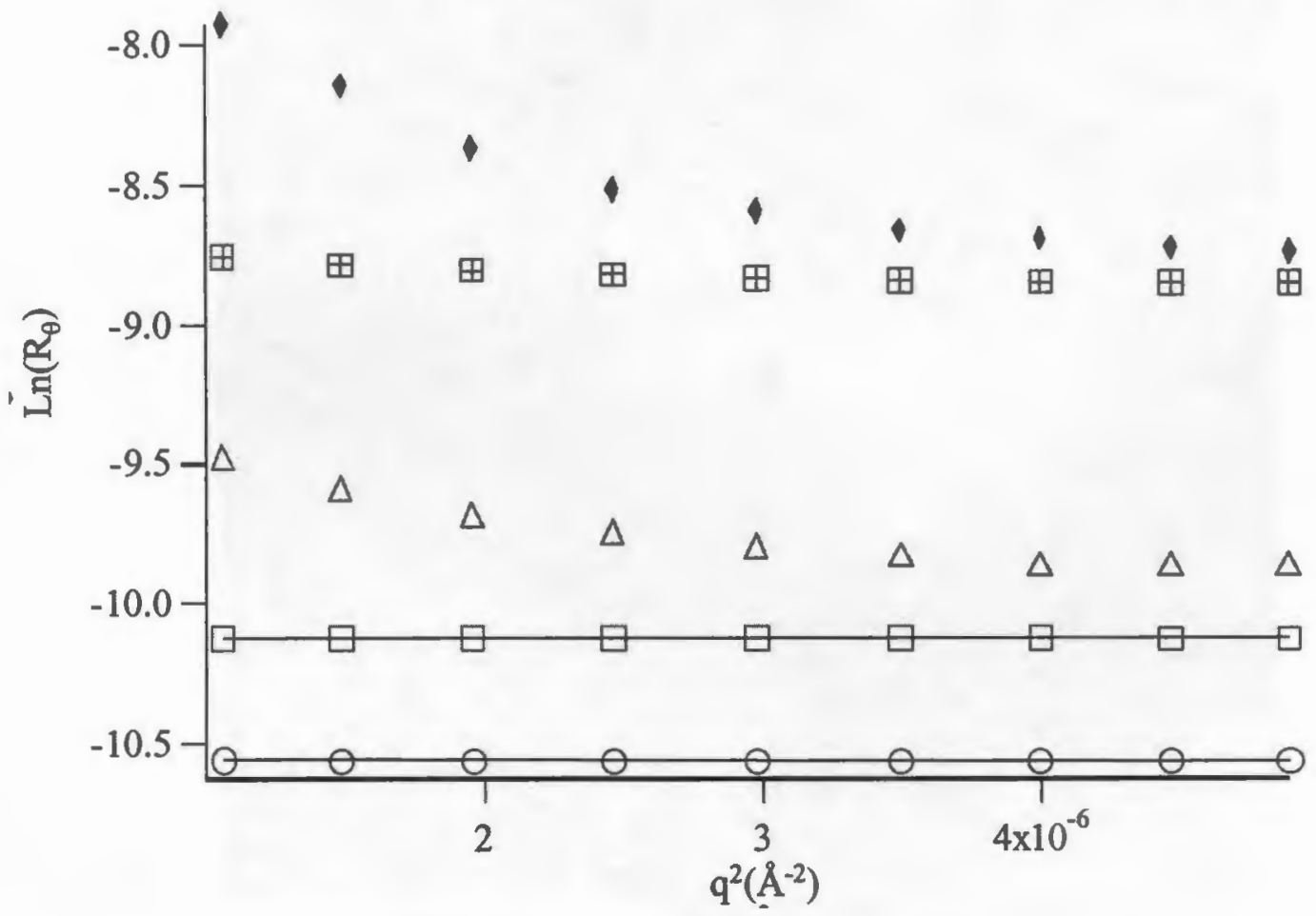

Figure III-2 Straight line fit (solid line) to the $\operatorname{Ln}\left(\mathrm{R}_{\theta}\right)$ versus $\mathrm{q}^{2}$ data for samples, (O) 0.01MAOT(sample1) and ( $\square$ ) $0.00125 \mathrm{M}$ Lecithin /0.00875M AOT (sample2). Slope of the fit decreases from sample1 to sample2 indicates increase in the radius of gyration with increasing lecithin content in the system. 


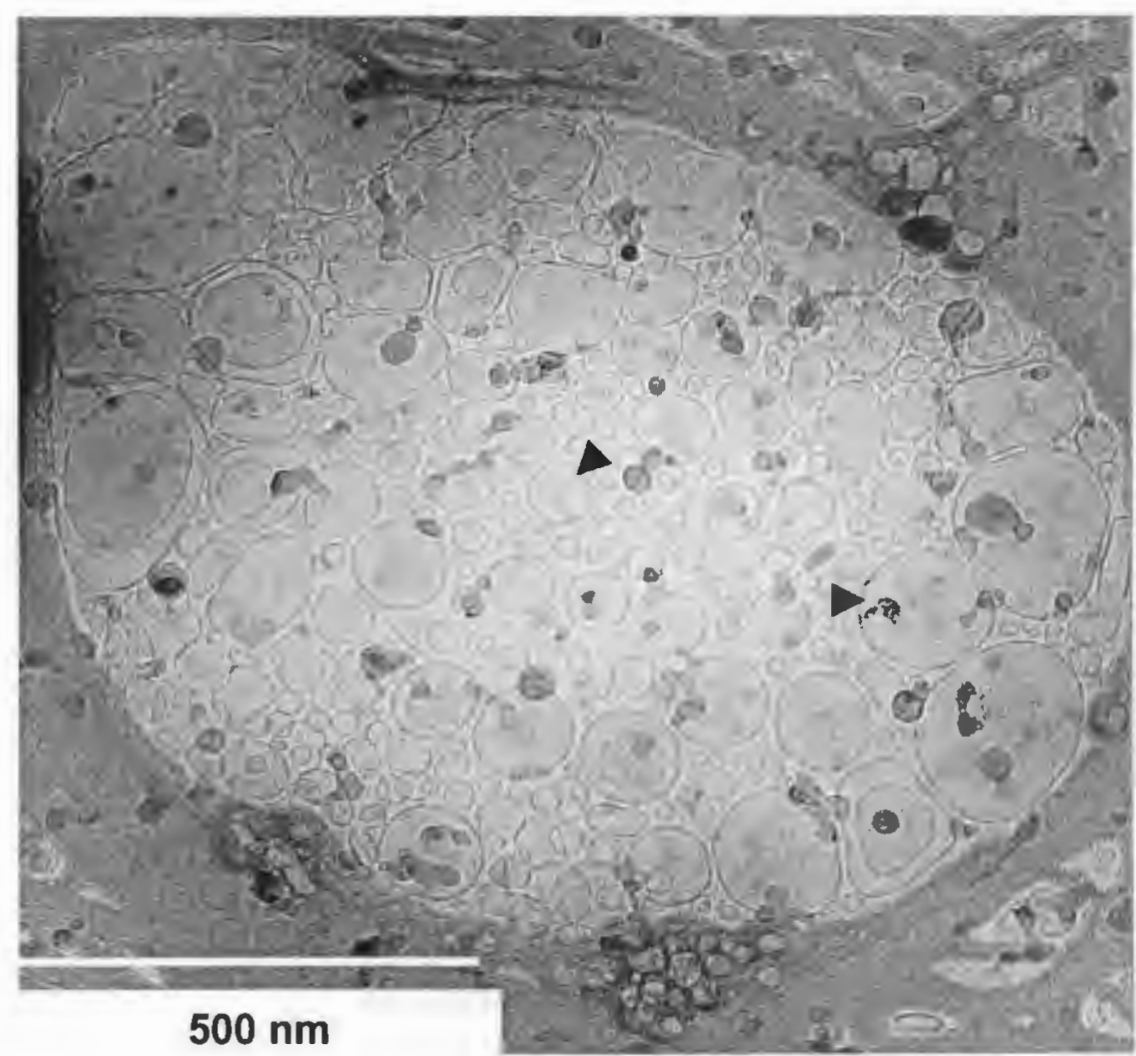

FigureIII-3A Cryo-TEM image showing vesicles(arrow heads) of sizes $20-300 \mathrm{~nm}$ in a thin vitrified film of the $24 \mathrm{mM}$ aqueous solution of cetyl trimethylammonium bromide (CTAB) and dodecyl benzene sulfonic acid (HDBS), mixed in a fixed ratio of 64:36 (CTAB:HDBS). 


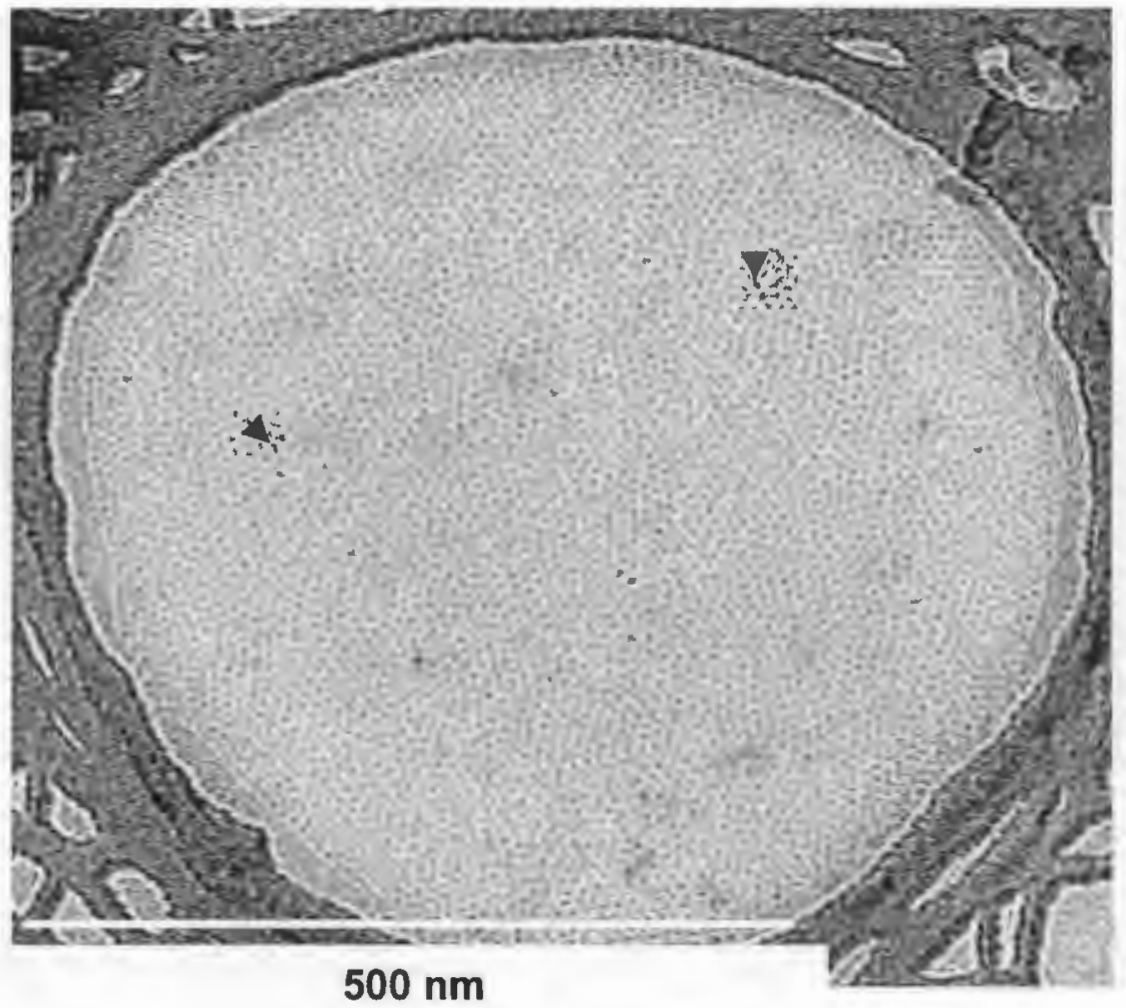

FigurellI-3B Cryo-TEM image showing micelles(arrow heads) of sizes $5-10 \mathrm{~nm}$ in a thin vitrified film of the system consisting of n-pentane, n-dodecane, octaethylene glycol dodecyl ether $\left(\mathrm{C}_{12}(\mathrm{EO})_{8}\right)$ and water, mixed in a fixed ratio of 1:1:2:22.67(by wt). 


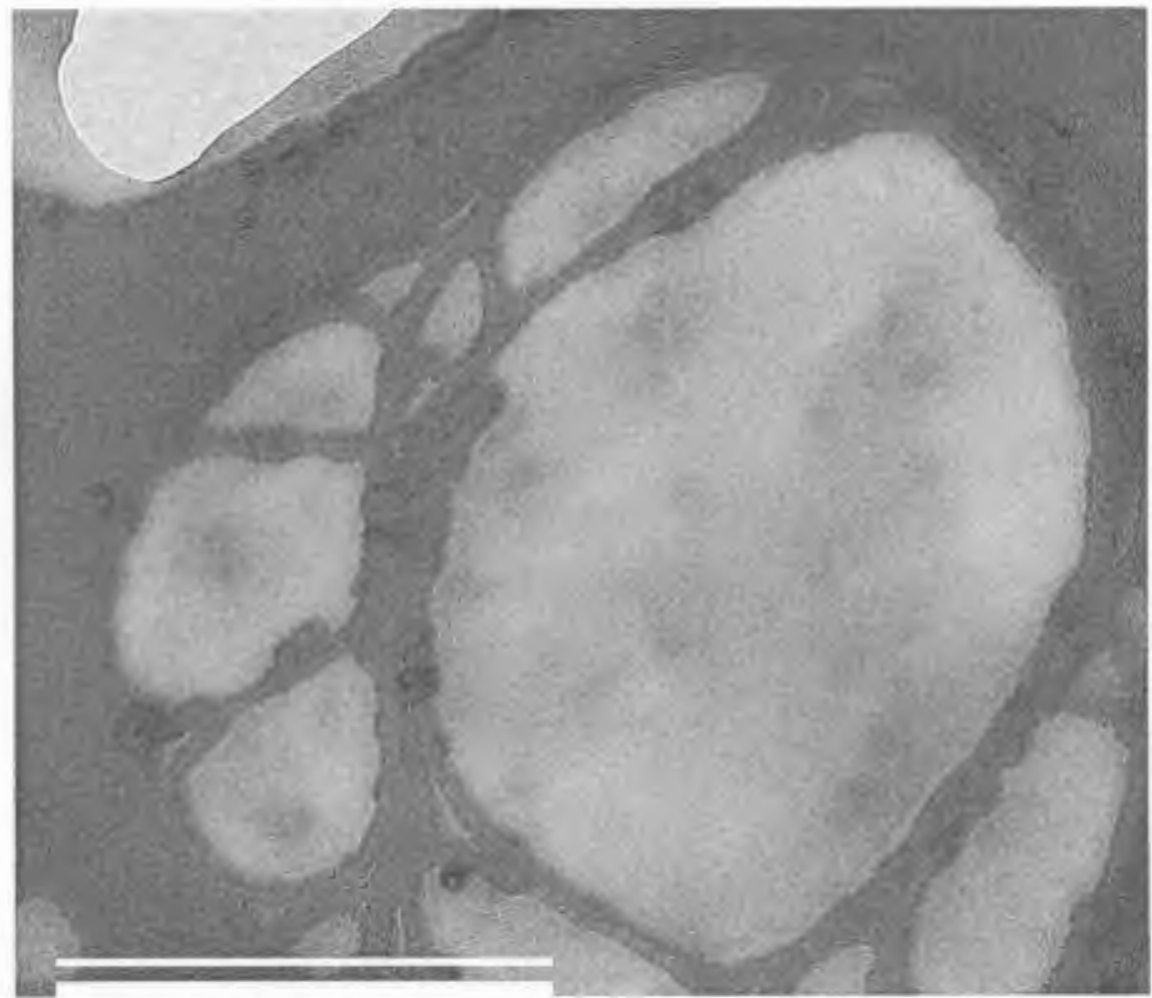

$500 \mathrm{~nm}$

FigureIII-4A Cryo-TEM image of $0.01 \mathrm{M}$ AOT system, showing a vitrified film of the sample. 


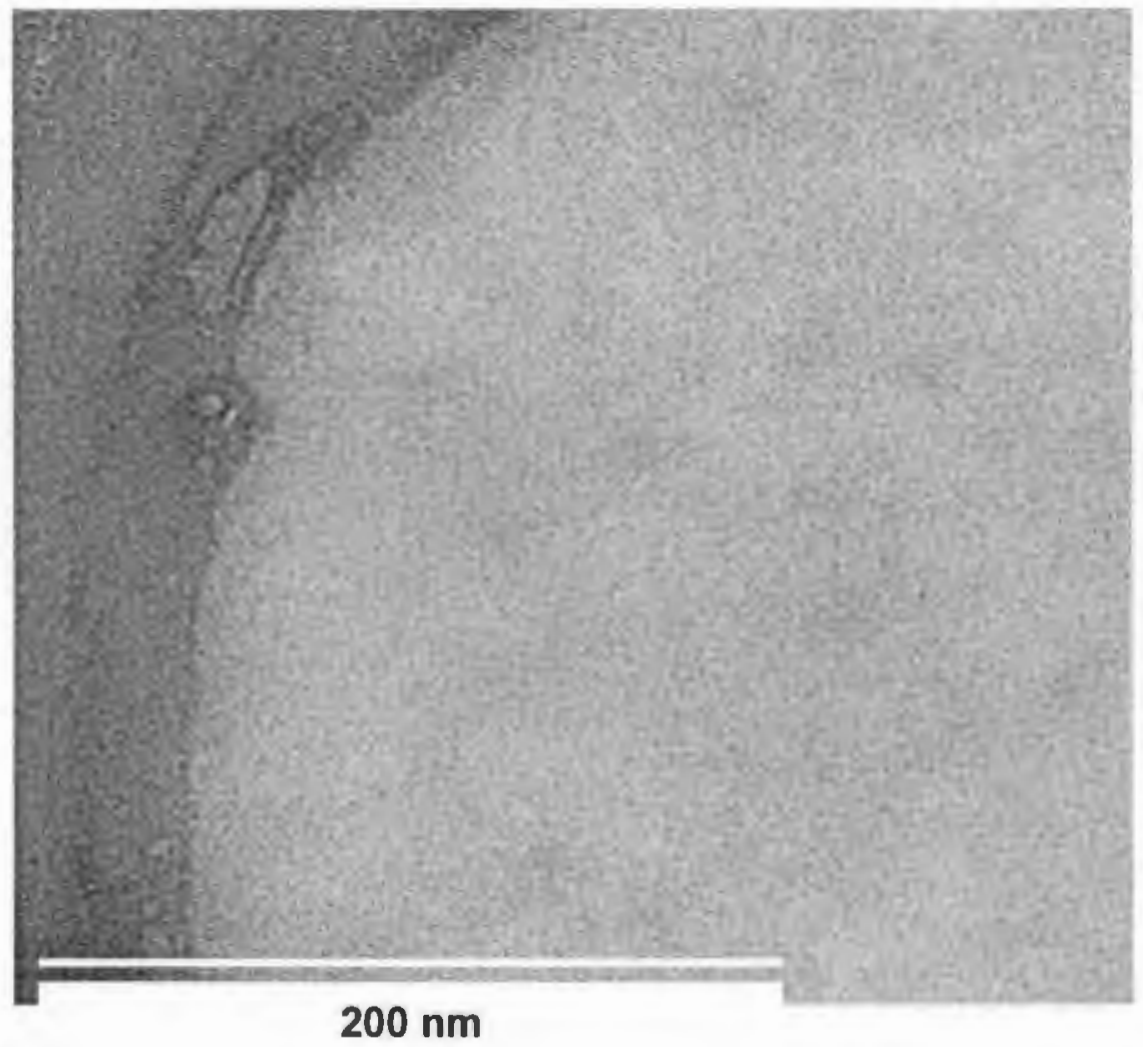

FigureIII-4B Cryo-TEM image of $0.00125 \mathrm{M}$ Lecithin/0.00875M AOT system, showing a thin vitrified film of the sample 


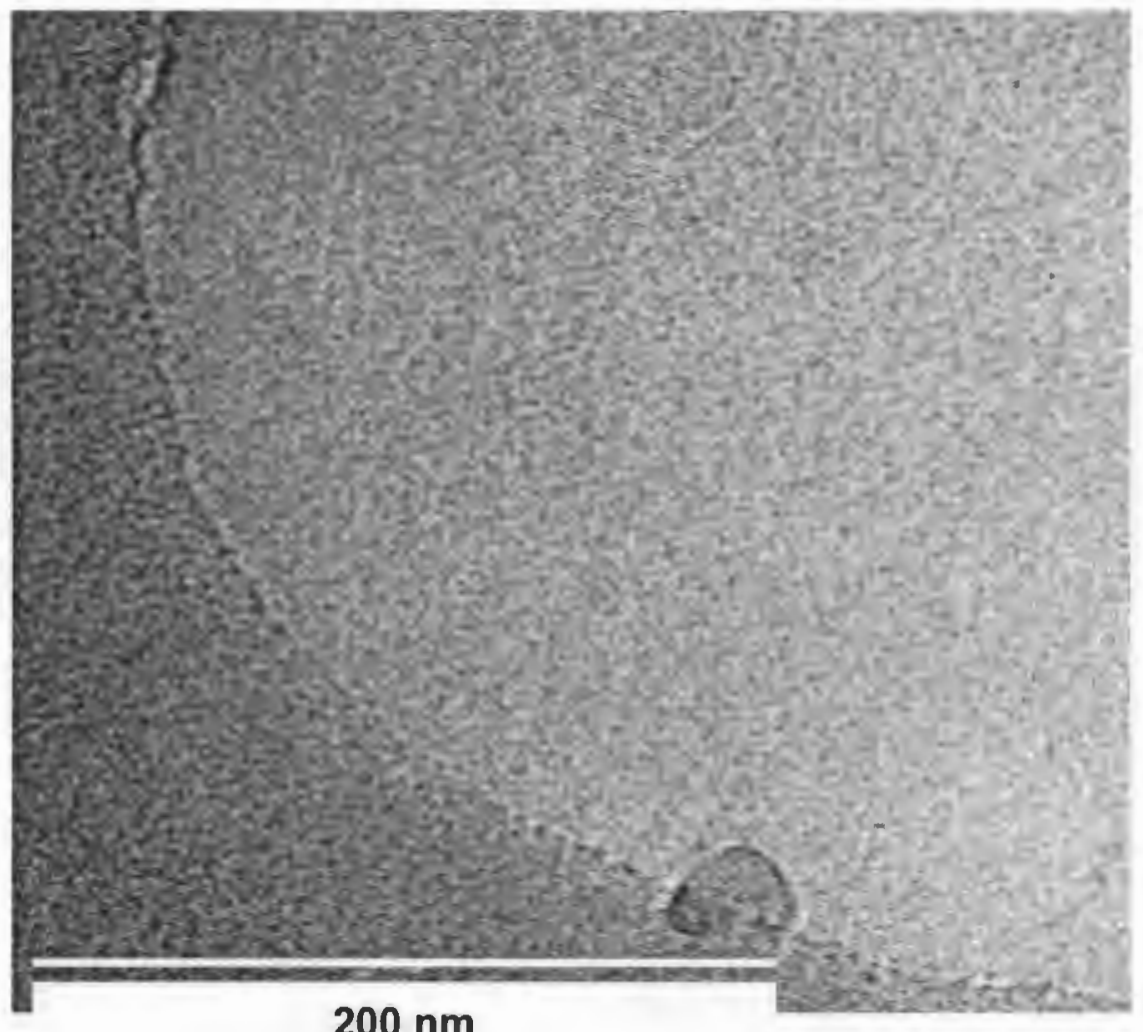

FigureIII-4C Cryo-TEM image of $0.0025 \mathrm{M}$ Lecithin/0.0075M AOT system, showing a vitrified film of the sample 


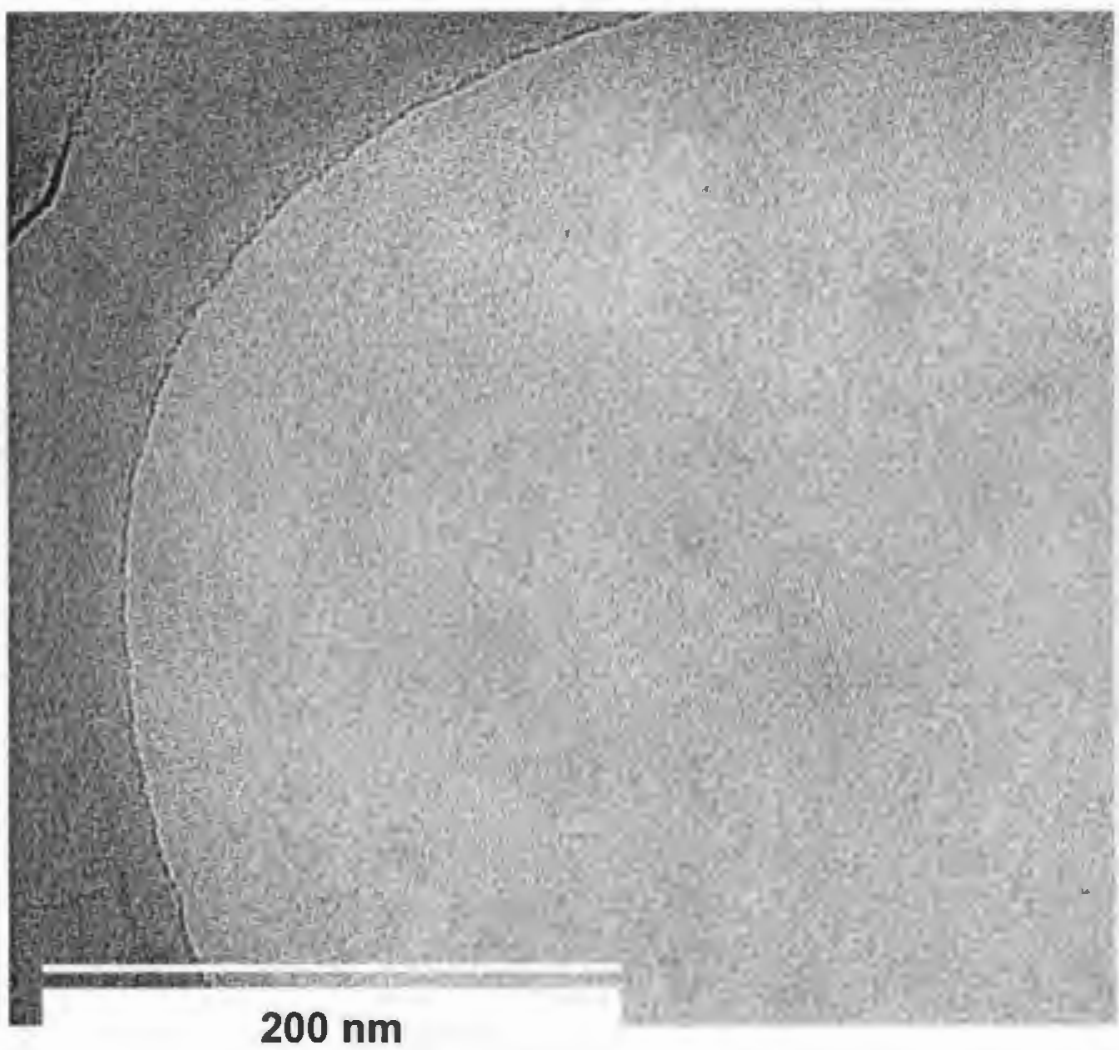

FigureIII-4D Cryo-TEM image of $0.00375 \mathrm{M}$ Lecithin/0.00625M AOT system, showing a thin vitrified film of the sample 


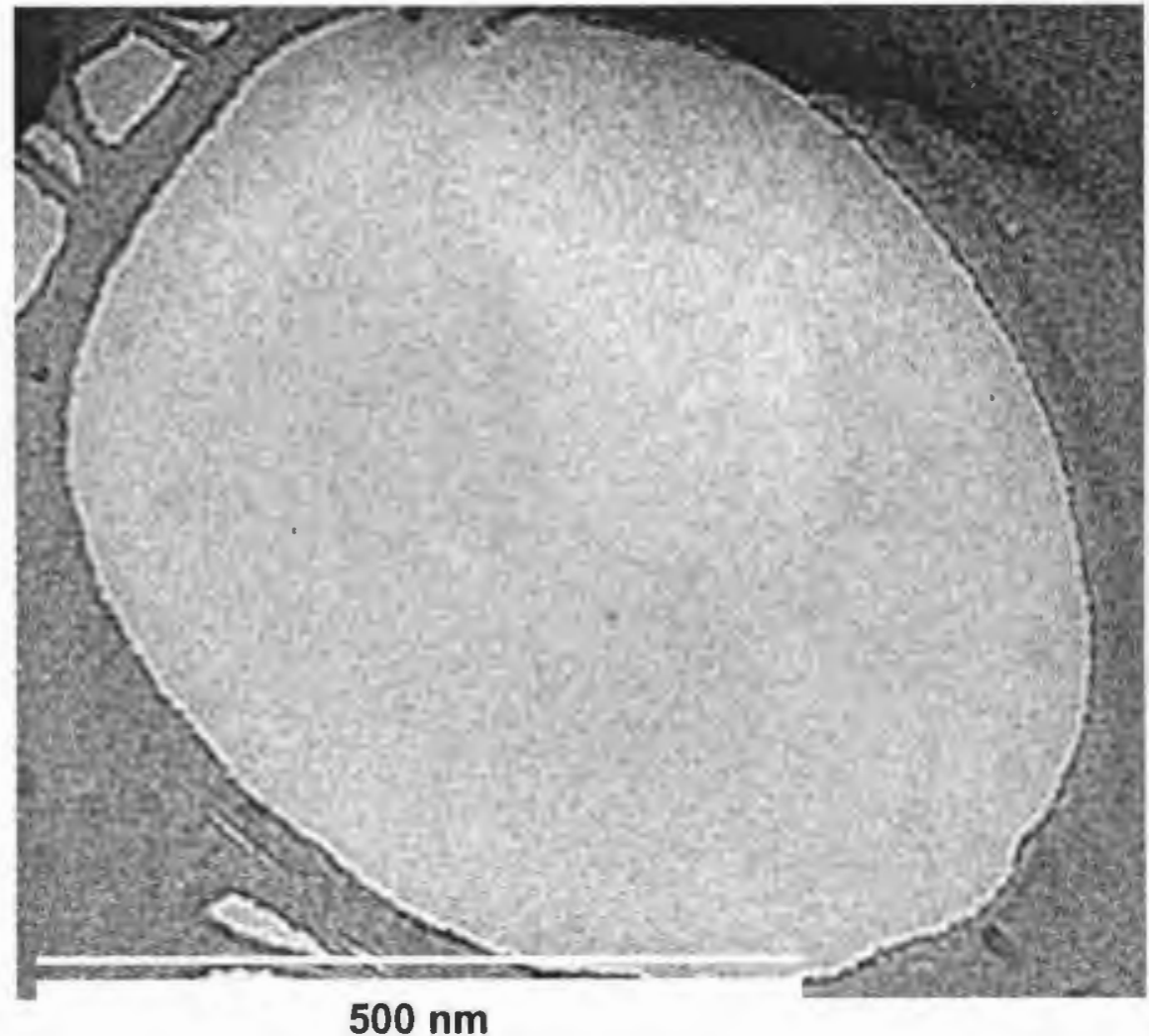

FigureIII-4E Cryo-TEM image of $0.005 \mathrm{M}$ Lecithin/0.005M AOT system, showing a thin vitrified film of the sample 


\section{References}

${ }^{1}$ Imae, T., Coll. Surf. A, 1996, 109, 291-304.

${ }^{2}$ Iampietro, D.J.; Brasher, L.L.; Kaler, E.W.; Stradner, A.; Glatter, O., J. Phys. Chem., 1998, 102, 3105-3113.

${ }^{3}$ Thomas, H.G.; Lomakin, A.; Blankschtein, D.; Benedek, G.B., Langmuir, 1997, 13, 209-215.

${ }^{4}$ Kakitani, M.; Imae, T.; Furusaka, M., J. Phys. Chem., 1995, 99, 16018-16023.

${ }^{5}$ Y. Talmon, Bur. Bunsenges. Phys. Chem. 100, 364-372 (1996) No. 3

${ }^{6}$ Xia, Y.; Goldmints, I.; Johnson, P. W.; Hatton, T. A.; Bose, A., Langmuir (in press)

${ }^{7}$ Regev, O.; Ezrahi, S.; Aserin, A.; Garti, N.; Wachtel, E.; Kaler, E. W.; Khan, A.; Talmon, Y., Langmuir 1996, 12, 668-674. 


\section{CHAPTER IV}

\section{FREEZE FRACTURE TEM AND DIFFERENTIAL SCANNING}

\section{CALORIMETRY STUDIES ON THE MIXED SURFACTANT GEL SYSTEM}

\section{IV-A Introduction}

The structural study of microstructured fluids is a major area of research in colloid science. As a working definition, a microstructured fluid is one in which one or more components of the fluid have organized on supermolecular scales, from one to hundreds of nanometer. Microstructured fluids arise in a number of physiological, biological, chemical, and physical systems as interfaces, films, foams, emulsions, suspensions, membranes, gels, and liquid crystals.

A system consists of two surfactants, 0.8M AOT(bis-2ethylhexyl sodium sulfosuccinate) and $0.42 \mathrm{M}$ lecithin(phosphatidylcholine) in isooctane, which demonstrates a novel transformation from a microemulsion to a rigid gel state with increasing water content of the system, falls in this category of a microstructured fluid. The microstructure of the gel state of this system has been characterized extensively via SANS. ' As either the water content or temperature is varied, the microstructure undergoes a transition from columnar hexagonal to lamellar phase.

Modern rapid cooling methods followed by freeze fracture replication techniques provides a direct visualization of the three dimensional structure of the particles or units that make up the system, while simultaneously revealing their 
orientation and distribution with molecular resolution. This is the direct imaging technique used to characterize the mixed surfactant gel system that is described in this chapter.

The other part of this chapter deals with the thermal properties of the system under observation. Differential scanning calorimetery (DSC) is used to detect any thermal transitions in the system as it goes from one phase to another.

\section{IV-B Experimental section:}

\section{IV-B1 Chemicals:}

Lecithin (95\% pure, extracted from soybeans) was obtained from Avanti Polar Lipids, Inc. Bis (2-ethylhexyl) sodium sulfosuccinate (AOT) and 2,2,4trimethylpentane (isooctane - 99\% purity) were purchased from Sigma-Aldrich. Distilled and deionized water was used. All chemicals were used without further treatment and/or purification.

\section{IV-B2 Sample preparation:}

Typical compositions of the samples were as follows: $0.85 \mathrm{M}$ AOT $(1.89 \mathrm{~g})$ and $0.42 \mathrm{M}$ of lecithin $(1.59 \mathrm{~g})$ placed in $5 \mathrm{ml}$ of isooctane. This mixture was sonicated in a warm water $\left(38{ }^{\circ} \mathrm{C}\right)$ bath until completely dissolved and a clear yellow liquid was formed. These amounts were fixed for all of the systems analyzed. Water was added in incremental measured quantities (ca. $0.5 \mathrm{ml}$ per increment) in order to obtain the desired $W_{0}\left(=\left[\mathrm{H}_{2} \mathrm{O}\right] /[\mathrm{AOT}]\right)$ values. The $W_{0}$ values used were 130,150 , 
and 170 . Once the $\mathrm{H}_{2} \mathrm{O}$ was added, the samples were sonicated in a warm water bath and vortexed until a clear yellow liquid was obtained. This process was repeated until the total required amount of $\mathrm{H}_{2} \mathrm{O}$ was added for the corresponding $W_{0}$ value. The samples were then removed from the water bath and allowed to cool to ambient conditions. The samples were all in the gel state.

\section{IV-B3 Experimental methods:}

\section{IV-B3.1 Freeze fracture transmission electron microscopy (FFTEM):}

A small amount of sample (maintained at $25^{\circ} \mathrm{C}$ and $40^{\circ} \mathrm{C}$ ) was put on a sample pan and rapidly frozen in liquid nitrogen. The frozen material is then fractured, at low temperature $\left(-165^{\circ} \mathrm{C}\right)$ and at ultra high vacuum, with the aid of the glass knife, inside the freeze fracture equipment (Central microscopy facility, University of Massachusetts, Amherst). The fractured surface was then replicated by a platinum coating $(4-5 \mathrm{~nm})$ followed by a carbon backing $(15-20 \mathrm{~nm})$. The remaining sample was then dissolved, using methanol, and the platinum replica supported by a carbon film was collected on the electron microscope grid for direct imaging via transmission electron microscopy (TEM). Imaging was done using JOEL 1200 TEM.

\section{IV-B3.2 Differential scanning calorimetery (DSC):}

Measurements were done using Differential Scanning Calorimeter (v. DSCQ100 series) from TA Instruments. The instrument calibration was performed using an indium standard. For each sample a single stainless steel sample pan from Cole Parmer was designated. Baselines were generated for all the samples; each empty 
sample pan was equilibrated at 10 Degrees Celsius than kept at that temperature for 3 minutes then heated at a constant ramp rate of $5^{\circ} \mathrm{C} /$ minute. Weighed amounts of the sample were then sealed in the stainless steel pans and equilibrated at the starting temperature of $10^{\circ} \mathrm{C}$ for 3 minutes prior to the initiation of the heating scans. Heat flow differences between the sample and reference pans were recorded over the temperature range of $10-60^{\circ} \mathrm{C}$.

\section{IV-C Analysis:}

The DSC works by measuring the temperature of two pans, one reference and one containing the sample. In order to increase the temperature of either pan, heat must be added. Intuitively, the pan containing the sample will require more heat to be added to it than the empty pan. The DSC measures this heat flux and records it.

Amount of heat added to the system per unit time can be related to its temperature change by the following equation,

$$
\frac{\Delta H}{\Delta t}=m c_{p} \frac{\Delta T}{\Delta t}
$$

where $\Delta H / \Delta t$ is the rate of heat added to the system, $m$ is the mass of the system, $c_{p}$ is the specific heat capacity of the system and $\Delta \mathrm{T} / \Delta \mathrm{t}$ is the temperature ramp rate.

Knowing the ramp rate with heat flow information and the mass of the system, specific heat capacity $\left(c_{p}\right)$ of the system can be determined. 


\section{IV-D Results and discussion:}

Figure IV-1 shows a freeze fracture TEM image of $\mathrm{W}_{0}=170$ samples at $40^{\circ} \mathrm{C}$. Parallel lines running throughout the image clearly show the evidence of the lamellar phase in the system at this water content. The other samples including $W_{0}=130$ and $\mathrm{W}_{0}=150$ did not provide any adequate details of the microstructure and that is why those images are not reported here.

DSC experimental results of the specific heat capacities for all the three samples are presented in FigureIV-2. The experimental error associated with the specific heat capacity hides out any major changes in the heat capacity of the system with the temperature. The experimental average specific heat capacity, for the observed temperature range, for all the samples are reported in Table IV-1 and compared with the specific heat capacities, calculated using simple mixing rule. Within the experimental error all the samples shows a good accord with the theoretical values.

\section{IV-E Conclusions:}

Freeze fracture transmission electron microscopy has proven to be a successful technique in terms of imaging out this system. Further efforts in this field may give proper details of the microstructure in the gel system. DSC, on the other hand, may 
provide evidence of the heat changes involved with the phase transitions in the gel phase with increasing temperature of the system. 


\begin{tabular}{|c|c|c|c|c|c|c|}
\hline Sample & $\begin{array}{c}\text { Amount of } \\
\text { Isooctane } \\
(\mathrm{ml})\end{array}$ & $\begin{array}{c}\text { Amount of } \\
\text { AOT } \\
(\mathrm{gm})\end{array}$ & $\begin{array}{c}\text { Amount of } \\
\text { Lecithin } \\
(\mathrm{gm})\end{array}$ & $\begin{array}{c}\text { Amount } \\
\text { of Water } \\
(\mathrm{ml})\end{array}$ & $\begin{array}{c}\text { Average specific } \\
\text { heat capacity }\left(\mathrm{c}_{\mathrm{p}}\right) \\
\text { over temperature } \\
\text { range }\left(20-60^{\circ} \mathrm{C}\right) \\
\text { joules } / \mathrm{gm}^{\circ} \mathrm{C}\end{array}$ & $\begin{array}{c}\text { Calculated } \\
\text { specific heat } \\
\text { capacity }\end{array}$ \\
\hline $\mathrm{W}_{0}=130$ & 5 & 1.89 & 1.59 & 9.89 & 3.4 & 3.4 \\
\hline $\mathrm{W}_{0}=150$ & 5 & 1.89 & 1.59 & 11.41 & 3.6 \\
\hline $\mathrm{W}_{0}=170$ & 5 & 1.89 & 1.59 & 12.94 & 3.5 & 3.75 \\
\hline
\end{tabular}

Table IV-1 Comparison of the experimental average specific heat capacity for all the samples with the specific heat capacity calculated using simple mixing rule. 


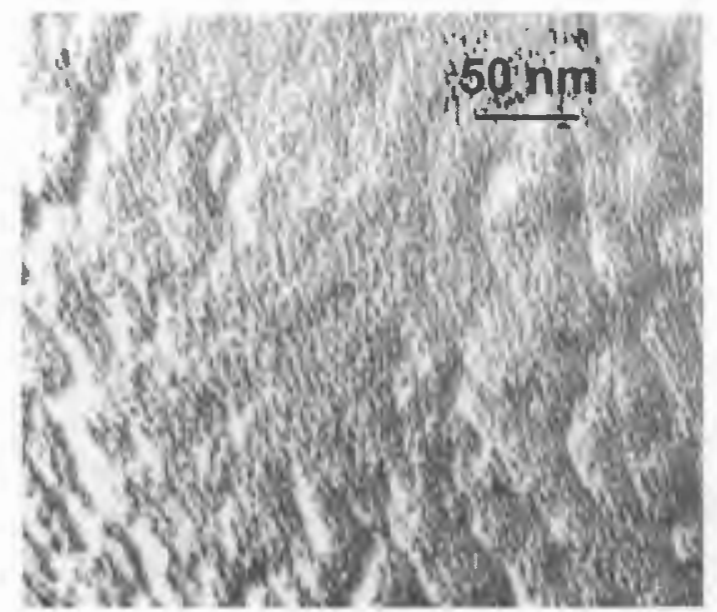

Figure IV-1 Freeze fracture TEM image of the sample $\left(\mathrm{W}_{0}=170\right)$ at $40^{\circ} \mathrm{C}$, shows clear evidence of lamellar microstructure. 


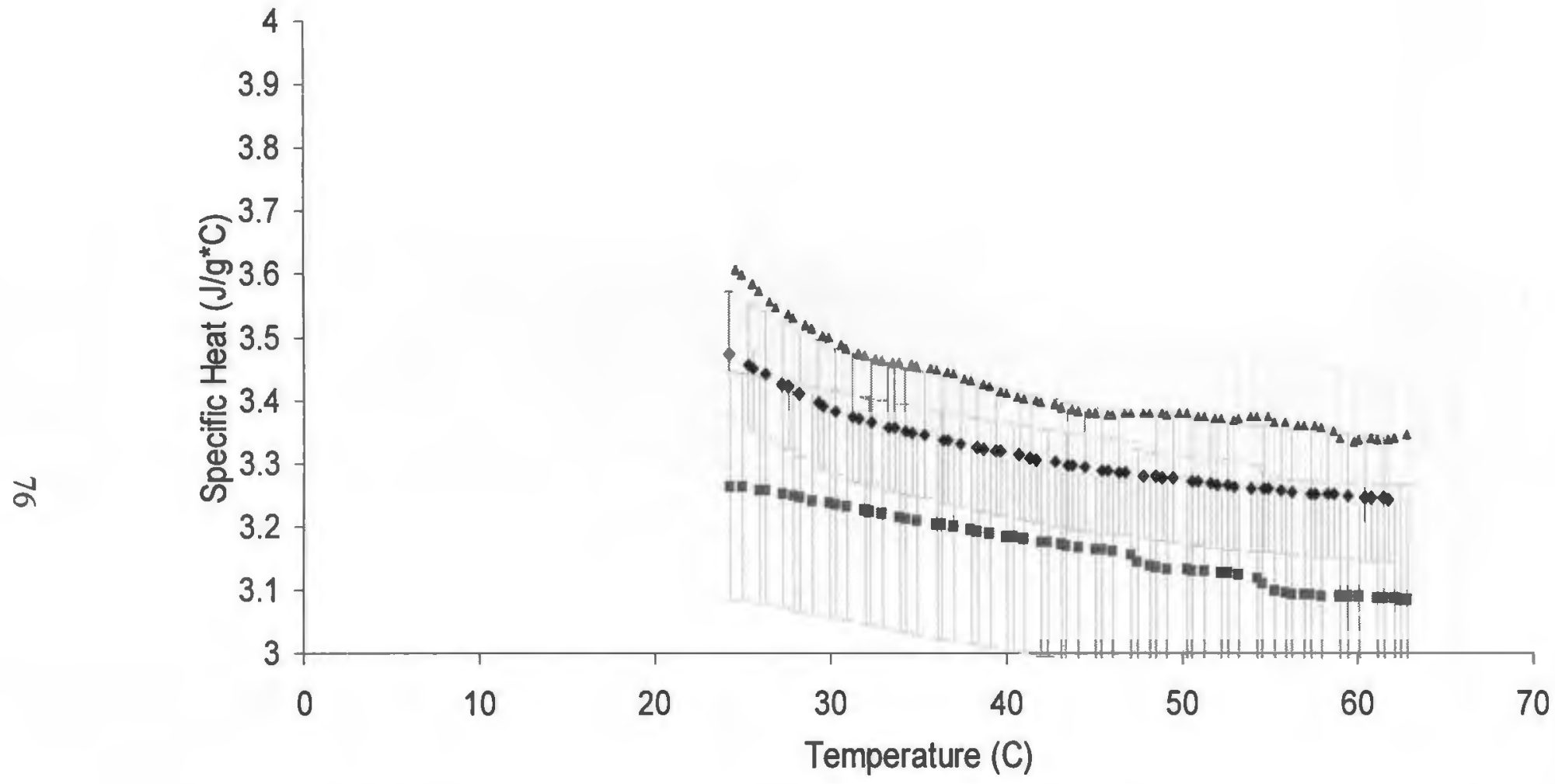

Figure IV-2 Specific heat capacity versus temperature data, using DSC, for sample $\left(\mathrm{W}_{0}=130, \bullet\right)$, for sample $\left(\mathrm{W}_{0}=150, \square\right)$ and for sample $\left(\mathrm{W}_{0}=170, \mathbf{\Lambda}\right)$. Experimental error hides out any detectable change in the heat capacity with temperature for all the samples. 


\section{References:}

' Simmons, B., Irvin, G. C., Li, S., John, V.T., McPherson, G.L., Balsara, N., Agarwal, V., Bose, A. Langmuir, 2002,18, 624-632. 


\section{Bibliography}

Bergstrom, M.; Pedersen, J.S., Journal of Physical Chemistry B 2000, 104, 41554163.

Bergstrom, M.; Pedersen, J.S.; Langmuir, 1998, 14, 3754-3761.

Berlepsch, H. v.; Bottcher, C.; Ouart, A.; Regenbrecht, M.; Akari, S.; Keiderling, U.; Schnablegger, H.; Dahne, S.; Kirstein, S. Langmiur, 2000, 16, 5908-5916.

Bumajdad, A.; Eastoe, J.; Heenan, R.K.; Lu, J.R.; Steytler, D.C.; Egelhaaf, S. Journal of Chemical Society, 1998, 94 (15), 2143-2150.

D. Capitani, A.L. Segre, R. Sparapani, M. Giustini, R. Scartazzini, P.L. Luisi, Langmuir 1991, 7, 250.

De Geyer, A.; Tabony, Journal of Chemical Physics Letters, 1985, 113, 83.

De, T.K.; Maitra, A., Advancement in Colloid and Interface Sciences, 1995, 59, 193.

Freeman, K.S.; Tan, N.C.; Trevino, S.F.; Kline, S.; McGown, L.B.; Kiserow, D.J. Langmuir, 2001.

Griffith, W. L.; Triolo, R.; Compere, A. L. Physical Review A, 1987, 35, 2200 Iampietro, D.J.; Brasher, L.L.; Kaler, E.W.; Stradner, A.; Glatter, O., Journal of Physical Chemistry, 1998, 102, 3105-3113

Guinier, A.; and G. Fournet, Small Angle Scattering of X-rays (wiley-Interscience, NewYork), 1955 
Imae, T. Colloid and Surface A, 1996, 109, 291-304.

Israelachvili, J.N. Intermolecular and Surface Forces, Academic Press, New York, 1992.

Jouffray, J.; Levinson, P.; De Gennes, P.G. Journal of Physics, 1982, 43, 1241.

Kakitani, M.; Imae, T.; Furusaka, M., Journal of Physical Chemistry, 1995, 99, 16018-16023.

Kaler, E. W., Billman, J. F., Fulton, J. L., Smith, R. D., Journal of Physical Chemistry 1991, 95, 461

Koehler, R.D.; Raghavan, S.; Kaler, E.W. Journal of Physical Chemistry, 2000, 104, $11025-11044.1$

Kotlarchyk, M.; Stephens, R.B.; Huang, J.S., Journal of Physical Chemistry 1988, $92,1533$.

Kresge, C.T.; Leonowicz, M.E.; Roth, W.J.; Vartuli, J.C.; Beck, J.S., Nature, 1994, 368,321 .

Kumar, S.; Aswal, V.K.; Goyal, P.S.; Din, K. Journal of Chemical Society, 1998, 94(6), 761-764.

Lagues, M.; Ober, R.; Taupin, C. Journal of Physics Letters, 1978, 39, L-487.

Lee, C. T.; K. P. Johnston, H. J. Dai, H. D. Cochran, Y. B. Melnichenko, G. D. Wignall, Journal of Physical Chemistry B 2001, 105, 3545

Lise Arleth and Pedersen, J.S., Journal of Applied Crystallography 2000, 33, 650-652. 
Li, S.; Irvin, G.C.; Simmons, B.; Rachakonda, S.; Ramannair, P.; Banerjee, S.; John, V.T.; McPherson, G.L.; Zhou, W.; Bose, A. Colloids and Surfaces A, 2000, 174, 275.

Lopez-Quintela, M.A.; Rivas, J., Journal of Colloid and Interface Science, 1993, 158, 446.

Pileni, M.P., Langmuir, 1997, 13, 3266.

Regev, O.; Ezrahi, S.; Aserin, A.; Garti, N.; Wachtel, E.; Kaler, E. W.; Khan, A.; Talmon, Y., Langmuir 1996, 12, 668-674.

Scartazzini, R. and P. L. Luisi, Journal of Physical Chemistry 1988, 92, 829.

Schmuhl, N.; Davis, E.; Cheung, H.M., Langmuir, 1998, 14, 757.

Schurtenberger, P.; Scartazzini, R.; Luisi, P.L. Rheol. Acta. 1989, 28, 372. Luisi, P.L.; Scartazzini, R.; Haering, G.; Schurtenberger, P. Colloid and Polymer Science $1990,268,356$.

Simmons, B., Irvin, G. C., Li, S., John, V.T., McPherson, G.L., Balsara, N., Agarwal, V., Bose, A. Langmuir, 2002,18, 624-632.

Simmons, B., Li, S., John, V., McPherson, G., A. Bose, 2002, in press, Nanoletters Talmon,Y.; Bur. Bunsenges. Physical Chemistry 100, 364-372 (1996) No. 3

Thomas, H.G.; Lomakin, A.; Blankschtein, D.; Benedek, G.B., Langmuir, 1997, 13, 209-215.

Wabel, C., Ph.D. Dissertation, University of Erlangen, 1998. 
Walsh, D.; Hopwood, J.D.; Mann, S., Science, 1994, 264, 1576.

Xia, Y.; Goldmints, I.; Johnson, P. W.; Hatton, T. A.; Bose, A., Langmuir (in press) 